\title{
Elaboração e aprovação de planos de educação no Brasil: do nacional ao local
}

\author{
Donaldo Bello de Souza a \\ Janaína Specht da Silva Menezes ${ }^{b}$
}

\section{Resumo}

Este artigo visa à análise da elaboração e aprovação dos Planos Estaduais de Educação (PEEs) sancionados durante a vigência do Plano Nacional de Educação (PNE) 2001-2010. Sob perspectiva exploratória e por meio da análise de conteúdo desses planos e de suas leis de criação, busca contribuir para as adequações e formulações que o PNE 2014-2024 veio a implicar. À guisa de conclusão, traça o perfil, por um lado, das debilidades documentais expostas por esses PEEs, apontando lacunas e imprecisões que dificultam inferências sobre o seu processo de construção e, por outro, dos problemas identificados a partir da análise desse próprio processo. Postula, em termos gerais, que a construção desses PEEs parece ter se revestido de importante significado histórico e sociopolítico no âmbito dos estados envolvidos, marcado pela mobilização da sociedade civil local, mas que ainda demanda aprofundamento analítico, especialmente em face dos desafios postos pelo novo PNE.

Palavras-chave: Planos estaduais de educação (PEEs). Planos nacionais de educação (PNEs). Participação social. Gestão democrática da educação.

\section{Introdução}

Aprovado por meio da Lei ${ }^{\circ}$ 13.005, de 25 de junho de 2014 (BRASIL, 2014), o Plano Nacional de Educação (PNE) 2014-2024 não apenas traz à vista novos desafios ao planejamento educacional no Brasil, mas também antigos reptos, a começar pela determinação de que "Os Estados, o Distrito Federal e os Municípios deverão elaborar seus correspondentes planos de educação, ou adequar os planos já aprovados em lei, em consonância com as diretrizes, metas e estratégias previstas neste PNE" (BRASIL, 2014, art. $8^{\circ}$ ), no prazo de um ano contado a

\footnotetext{
a Universidade do Estado do Rio de Janeiro - UERJ, Faculdade de Educação, Departamento de Políticas Públicas, Gestão e Avaliação da Educação da Faculdade de Educação. Rio de Janeiro, Rio de Janeiro, Brasil.

b Universidade Federal do Estado do Rio de Janeiro - Unirio, Faculdade de Educação. Rio de Janeiro. Rio de Janeiro, Brasil.
} 
partir da publicação desta lei, isto mediante "ampla participação de representantes da comunidade educacional e da sociedade civil” (BRASIL, 2014, art. $7^{\circ}, \S 2^{\circ}$ ).

Sobre os Planos Estaduais de Educação (PEEs), é possível afirmar que pouco se sabe a respeito do seu processo de elaboração e aprovação, tampouco acerca da configuração regional assumida e sobre o papel que vieram a desempenhar na implementação do PNE 2001-2010 - Lei no 10.172, de 9 de janeiro de 2001 (BRASIL, 2001), embora, entre outras avaliações, o balanço realizado pelo Conselho Nacional de Educação $(\mathrm{CNE})^{1}$ sobre este plano nacional aponte a sua dissociação em relação aos PEEs, e também aos Planos Municipais de Educação (PMEs) como um importante problema que veio a obstaculizar a sua efetiva implantação no País (BRASIL, 2009).

Segundo dados concernentes ao levantamento realizado, em 2010, pelo Observatório da Educação da Organização Não Governamental (ONG) Ação Educativa $^{2}$, e atualizados (em abril de 2014) pelos autores deste artigo ${ }^{3}$, apenas 12 estados da federação (46\%) possuíam PEEs aprovados por lei, excluindo-se, também, o Distrito Federal, fazendo-se apenas presente, na Região Sudeste, no Rio de Janeiro e em Minas Gerais; na Região Nordeste, em Alagoas, na Bahia, na Paraíba e em Pernambuco; na Região Norte, no Amazonas, Pará e no Tocantins; e, por fim, na Região Centro-Oeste, em Goiás, no Mato Grosso e no Mato Grosso do Sul, não sendo notado na Região Sul. Nas demais unidades federativas (54\%), o cenário corresponde a certo descaso do Poder Público estadual para com a importância do PEE, quer pelo Poder Executivo, quer pelo Poder Legislativo, isto em função da incipiência das iniciativas voltadas para a sua construção e, ainda, do desencontro ou inexistência de informações acerca do estado de sua constituição e/ou tramitação parlamentar (SOUZA; MENEZES, 2014), conforme mais adiante discutido.

Com base nos pouquíssimos estudos acadêmicos existentes sobre os PEEs, observa-se que a preocupação central das análises consiste, caracteristicamente, em examinar

\footnotetext{
Tal balanço, intitulado "Indicações para subsidiar a construção do Plano Nacional de Educação 2011-2020", veio a tornar-se público por meio da Portaria CNE/CP n 10, de 6 de agosto de 2009 (BRASIL, 2009), pautando-se em avaliações iniciais do PNE 2001-2010 efetivadas: em 2004, pela Comissão de Educação e Cultura da Câmara dos Deputados; em 2005, pelo próprio CNE; cobrindo o período 2005-2006, pela Secretaria de Educação Básica (SEB) do Ministério da Educação (MEC); em 2006, pelo Centro de Planejamento e Desenvolvimento Regional (CEDEPLAR) e, ainda, em 2005, pelo Instituto Nacional de Estudos e Pesquisas Educacionais Anísio Teixeira (INEP/MEC).

2 OBSERVATÓRIO DA EDUCAÇÃO. Acompanhe a situação do plano de educação de cada estado. São Paulo, 2010. Disponível em: <http://www.observatoriodaeducacao.org.br/index.php?view=article\&id=995\%3Aacompanhe-asituacao-do-plano-de-educacao-de-cada-estado\&option=com_content\&Itemid=98>. Acesso em: 28 set. 2013.

3 Registra-se que, nesta fase do levantamento documental, a pesquisa contou com importante participação da Profa. Dra. Maria Celi Chaves Vasconcelos - Universidade do Estado do Rio de Janeiro (UERJ)/Universidade Católica de Petrópolis (UCP).
} 
a problemática da participação sociopolítica na sua elaboração. Em termos gerais, esses trabalhos atestam a existência de certa fragilidade de práticas democráticoparticipativas voltadas para a elaboração coletiva desses planos. Por exemplo, no Paraná e em São Paulo - estados que não vieram a ter os seus PEEs aprovados ${ }^{4}-$, Arias (2007) e Dantas (2008), respectivamente, identificam práticas democráticas de cunho meramente representativo em torno da elaboração dos planos; em Alagoas, o exame de Souza (2007) sobre o processo de construção do PEE igualmente indica baixa mobilização sociopolítica relativa à elaboração local; e, por fim, no Rio de Janeiro, Valle, Menezes e Vasconcelos (2010) destacam o longo trâmite legislativo que culminou, após oito anos, na aprovação do PEE fluminense.

Decerto, os processos de participação tomados por alvo nos estudos acima mencionados constituem-se como resultados da influência de diversos movimentos democrático-populares iniciados ao longo das décadas de 1960 e 1970, manifestos em várias frentes de lutas sociais (CALDERÓN; MARIM, 2002; 2003), assim como de experiências remanescentes de alguns outros movimentos sociais dos idos de 1980 (GOHN, 1998, 2001) que, no seu conjunto, lograram êxito em estabelecer pressões em prol de ideais democráticos e de institucionalização de novas redes associativas e canais de participação popular na esfera gestão pública (DUARTE; SANTOS, 2014; LUCHMANN, 2007; MENDES, 2007; LAVALLE; HOUTZAGER; CASTELLO, 2006).

Partindo do princípio de que os PEEs consistem importantes instrumentos de gestão, cuja particularidade implica, de um lado, integrar objetivos e metas do plano nacional, traduzindo-os, portanto, para a realidade territorial do estado e, de outro, prever a sua articulação às demandas municipais, de modo a que essas localidades possam adequar o planejamento nacional às suas particularidades, o presente texto visa à análise do processo de elaboração e aprovação dos PEEs elaborados ao longo da vigência do PNE 2001-2010, mais adiante indicados, tomando por base, em exclusivo, o exame dos documentos relativos a esses planos e suas leis de criação, aprovados por suas respectivas Assembleias Legislativas ao longo do período de vigência do PNE 2001-2010 .

Todavia, cumpre destacar que as informações sobre o processo de elaboração e aprovação desses PEEs não se encontram disponibilizadas nos documentos

\footnotetext{
4 Disponível em: <http://www.observatoriodaeducacao.org.br/index.php?view=article\&id=995\%3Aacompanhe-asituacao-do-plano-de-educacao-de-cada-estado\&option=com_content\&Itemid=98>. Acesso em: 28 set. 2013.

5 Tal recorte temporal não considerou, portanto, PEEs aprovados após 2010, cujo direcionamento considerou-se potencialmente influenciado pelos delineamentos, mesmo que preliminares, do novo PNE (BRASIL, 2014) -, o que metodologicamente obstaculizaria as comparações analíticas pretendidas, já que o foco da investigação consistiu nas repercussões daquele primeiro plano na esfera estadual.
} 
mencionados de forma uniforme entre estas etapas e com densidade descritiva suficiente à realização de análises de maior complexidade, o que significa que, em alguns PEEs, obtiveram-se quantitativa e qualitativamente informações mais significativas do que em outros, e que as reflexões aqui levadas a efeito encontram-se, portanto, empiricamente condicionadas pelas limitações dessas fontes documentais. Por certo, para efeito de um estudo mais efetivo sobre o processo em questão, o contato com os diversos atores sociais envolvidos com a sua construção seria de grande valor instrumental e reflexivo, viabilizando, com isto, o resgate da complexidade que lhe é inerente. Isto implicaria, entre outros aspectos, a localização do conjunto desses atores sociais e, decerto, a pesquisa in loco nas capitais do conjunto de estados aqui enfocados, procedimentos que, por diversos motivos - inclusive por opção metodológica -, não foram considerados na consecução da pesquisa da qual o presente artigo derivou. Assim, trata-se de um estudo resultante de uma pesquisa de maior amplitude ${ }^{6}$, que, além da investigação sobre a elaboração e aprovação desses PEEs, visou ao exame das suas vinculações com outros instrumentos de gestão da educação e, ainda, aos processos de implantação, acompanhamento e avaliação, também com vistas a contribuir com alguns subsídios críticos às formulações e adequações que o novo PNE (BRASIL, 2014) implica para esses planos estaduais.

De natureza qualitativa e exploratória (KETELE; ROEGIERS, 1993), metodologicamente ancorado na análise de conteúdo (RODRIGUES, 2011; BARDIN, 2004), o estudo considerou a forma literal com que os dados se apresentaram nos documentos examinados (FRANCO, 2005). Ao longo do processo de análise, adotou-se o sistema de pattern-matching (emparelhamento), que consistiu na associação dos conteúdos selecionados aos modelos teórico-conceituais construídos, definidores das categorias e subcategorias temáticas, de modo a comparar os dados coletados ao modelo lógico elaborado (LAVILLE; DIONNE, 1999), ou seja, procedeu-se ao confronto da "configuração empírica observada" com a "configuração teórica predita" (CONTANDRIOPOULOS et al., 1997, p. 89), procurando-se, a um só tempo, atender às necessidades de definição de novas subcategorias ou de reformulação daquelas definidas a priori. Essas categorias encontram-se indicadas no Quadro 1, associadas às subcategorias que também servem à definição do seu conteúdo temático.

\footnotetext{
6 Referimo-nos à pesquisa denominada "Estudo crítico-exploratório sobre os Planos Estaduais de Educação (PEEs) no Brasil: contribuições para formulações e reformulações decorrentes do novo Plano Nacional de Educação (PNE)", desenvolvido pelo Núcleo de Estudos em Política e História da Educação Municipal (NEPHEM), da Faculdade de Educação da Universidade do Estado do Rio de Janeiro (UERJ), em conjunto com o Núcleo de Estudos - Tempos, Espaços e Educação Integral (NEEPHI), da Faculdade de Educação da Universidade Federal do Estado do Rio de Janeiro (UNIRIO), ao longo do período 2013-2014 (cf. SOUZA; MENEZES, 2014).
} 
Quadro 1. Categorias e subcategorias temáticas empregadas para a análise dos PEEs.

\begin{tabular}{|l|l|}
\hline Categorias & \multicolumn{1}{|c|}{ Subcategorias } \\
\hline \multirow{2}{*}{$\begin{array}{l}\text { Enquadramento Legal } \\
\text { do PEE }\end{array}$} & Lei de aprovação \\
\cline { 2 - 2 } $\begin{array}{l}\text { Princípios e Concepções } \\
\text { do PEE }\end{array}$ & Período de vigência \\
\cline { 2 - 2 } Construção do PEE & Justificativa e/ou Importância para o Sistema Estadual de Ensino \\
\hline & Data de início e término da elaboração \\
\cline { 2 - 2 } & Espaços de elaboração \\
\cline { 2 - 2 } & Formas de elaboração \\
\cline { 2 - 2 } & Processos de elaboração \\
\cline { 2 - 2 } & Atores sociais envolvidos no processo de elaboração \\
\hline Aprovação do PEE & Espaços de aprovação e publicação da lei de regulamentação \\
\cline { 2 - 2 } & Formas e canais de divulgação do plano aprovado \\
\hline
\end{tabular}

Fonte: Os autores (2014). ${ }^{7}$

Finalmente, cabe destacar que, além da presente introdução, o artigo se edifica por meio de outras quatro seções. A segunda, com base na revisão da literatura pertinente, aborda a elaboração e aprovação do PNE 2001-2010 para, na seção seguinte, enfocar a elaboração dos PEEs, neste caso considerando os atores sociais envolvidos, o início e término do processo, sua coordenação e formas e estratégias de efetivação. Na sequência, analisa a aprovação e disseminação dos PEEs no País, englobando aspectos como a sua avaliação preliminar, os espaços de aprovação, a estrutura dos planos aprovados e a sua divulgação para a sociedade. Por fim, a quinta seção, à guisa de conclusão, busca resgatar os elementos centrais das análises realizadas de modo a, criticamente, relacioná-los, traçando um perfil das debilidades documentais expostas por esses instrumentos e dos problemas identificados ao longo do processo de construção desses mesmos PEEs.

\section{Elaboração e aprovação do PNE 2001-2010}

As determinações legais relativas ao estabelecimento de um PNE encontram-se postas tanto na Constituição Federal (CF) de 1988 - "A lei estabelecerá o plano nacional de educação, de duração plurianual, visando à articulação e ao desenvolvimento do ensino em seus diversos níveis e à integração das ações do Poder Público [...]" (BRASIL, 1988, art. 214) -, quanto na Lei de Diretrizes e Bases da Educação Nacional (LDBEN) n 9.394, de 20 de dezembro de 1996 - "A União incumbir-se-á de: I - Elaborar o plano nacional de educação, em colaboração

\footnotetext{
Nota: Embora a categoria "Princípios e concepções do PEE" não tenha se constituído alvo central do presente estudo, diferentemente das demais categorias acima indicadas, veio a fornecer, em determinados casos, importantes elementos para a complementação das análises.
} 
com os estados, o DF e os municípios" (BRASIL, 1996, art. 9, I) e, ainda, "A União, no prazo de um ano a partir da publicação desta Lei, encaminhará, ao Congresso Nacional, o Plano Nacional de Educação, com diretrizes e metas para os dez anos seguintes, em sintonia com a Declaração Mundial sobre educação para Todos." (BRASIL, 1996, art. 87, § $1^{\circ}$ ). Em paralelo, a Lei n ${ }^{\circ} 9.131$, de 24 de novembro de 1995 (BRASIL, 1995, art. $7^{\circ}, \S 1^{\circ}$ ) incumbiu o CNE de "subsidiar a elaboração e acompanhar a execução do Plano Nacional de Educação".

O cumprimento dessas determinações legais veio implicar elaboração de duas propostas de PNE, submetidas ao Congresso Nacional por meio do Projeto de Lei (PL) n 4.155, de 10 de fevereiro de 1998 (BRASIL, 1998a) e do PL $n^{\circ} 4.173$, de 11 de fevereiro de 1998 (BRASIL, 1998b), de autoria, respectivamente, da sociedade civil organizada e do Poder Executivo federal, caracterizando-se, de acordo com Beisiegel (1999), no primeiro caso pela ampla participação social e pelo caráter de luta política e ideológica que exprime, enquanto que, no segundo caso, pelo comprometimento em relação à racionalidade administrativa das políticas educacionais do Ministério da Educação (MEC), tratando-se, portanto, conforme salientado por Cury (1988, p. 162), de "duas formulações opostas quanto às concepções, diretrizes e metas que as norteiam", embora, na interpretação de Beisiegel (1999, p. 220), ambos os PLs tenham procurado "legitimar-se na ampla participação da sociedade no seu processo de elaboração".

\subsection{Elaboração das propostas}

De acordo com Peroni e Flores (2014), Silva e Peroni (2014), Bollman (2010) e Mendonça (2002), o processo de participação sociopolítica nas lutas por uma educação pública gratuita e com qualidade social tem, no Brasil, como uma das suas maiores expressões, o Fórum Nacional em Defesa da Escola Pública (FNDEP), cuja mobilização se faz notar, por exemplo, na sua origem, por época da Constituinte - quando era denominado Fórum Nacional pela Constituinte -, passando, entre 1988 e 1996, à efetivação de esforços em torno da elaboração de uma proposta de LDBEN, culminando, entre 1996-1997, no importante protagonismo relativo à formulação de uma proposta para um PNE, que ficou conhecida como "Proposta da Sociedade Brasileira" (cf. FÓRUM, 1997). Tal proposta, sistematizada no âmbito da Comissão Organizadora do II Congresso Nacional de Educação (CONED) ${ }^{8}$, constituiu-se na "síntese do esforço coletivo resultante dos debates realizados nas diferentes instâncias organizativas, nos

8 O II CONED foi realizado em novembro de 1997, em Belo Horizonte (MG), pautando-se nas diretrizes formuladas pelo I CONED, também resultado de inúmeras atividades até então promovidas pelo FNDEP (PERONI; FLORES, 2014; BOLLMAN, 2010). 
diversos eventos programados em todo o país, tais como o I CONED', Seminários Temáticos Nacionais e Locais, debates etc.” (BOLLMAN, 2010, p. 661).

Já a proposta do Poder Executivo federal, que para Beisiegel (1999, p. 200) não necessariamente se apresenta "como um projeto do Governo, mas como produto de ampla participação de professores, estudantes, dirigentes de estabelecimentos escolares, organizações da sociedade civil e do Conselho Nacional de Educação" - mas que, conforme sinalizam Davies (2014), Valente e Romano (2002) e Saviani (1988), acabou por reforçar a política do Governo Federal então em vigência -, utilizou-se, para as suas discussões, de documentos resultantes da participação do País em eventos internacionais patrocinados por organismos como Programa das Nações Unidas para o Desenvolvimento (PNUD), Nações Unidas para a Educação, Ciência e a Cultura (UNESCO) e Fundo das Nações Unidas para a Infância (UNICEF) ${ }^{10}$. Como resultado, o MEC divulgou documento contendo, entre outros, proposta para a discussão do PNE, intitulado "Plano Nacional de Educação: proposta inicial dos procedimentos a serem seguidos" (BRASIL, 1997), incluindo indicações de estratégias para a elaboração do plano em questão, sistemáticas de trabalho, cronogramas, além das propostas de metas para o plano propriamente dito (SAVIANI, 1998). Para este autor, tal proposta se limitava a reiterar a política educacional que vinha sendo levada a efeito pelo MEC e que implica a compreensão dos gastos públicos, a transferência de responsabilidades, especialmente de investimento e manutenção do ensino para Estados, Municípios, iniciativa privada e associações filantrópicas, ficando a União com as atribuições de controle, avaliação, direção e, eventualmente, apoio técnico e financeiro de caráter subsidiário e complementar (ibid., p. 84).

\subsection{Aprovação pelo Poder Legislativo}

O trâmite dos PLs no 4.155/1998 (BRASIL, 1998a) e nº 4.173/1998 (BRASIL, 1998b) na Câmara dos Deputados implicou, logo no início das discussões parlamentares, a apresentação de 37 Emendas ao primeiro PL e, em 1999, mais outras oito emendas, nenhuma direcionada ao PL do Governo Federal. Após um período de audiências, reuniões especiais, sugestões de estudo e diversas outras

\footnotetext{
9 O I CONED foi realizado no período de julho a agosto de 1996, também em Belo Horizonte (MG), com mais de 6 mil participantes, com vistas à organização de intervenções nos processos de elaboração e tramitação da LDBEN, então em curso, assim como dar início à sistematização das diretrizes educacionais articuladas à proposição do PNE em questão (BOLLMAN, 2010).

${ }^{10}$ Um desses eventos consistiu na chamada "Conferência de Jomtien" (Jomtien - Tailândia, em 1990), cujo Documento Final viria a ser conhecido como Declaração de Jomtien (UNESCO, 1998), vindo a servir de referência no Brasil para o Plano Decenal de Educação para Todos (PDET) 1993-2003 (BRASIL, 1993) e, a um só tempo, para o PNE 2001-2010 (BRASIL, 2001). Muitos dos princípios deste PNE vieram a ser reforçados pelo chamado Compromisso de Dakar, documento produto da realização do Fórum Mundial sobre Educação (Dakar - Senegal, em 2000), também realizado pela UNESCO (UNESCO, 2001), agora em conjunto com o Conselho Nacional de Secretários de Educação (CONSED) e a Organização Não Governamental (ONG) Ação Educativa (FÓRUM, 2001).
} 
emendas ${ }^{11}$, que chegou a tardar cerca de 26 meses, o processo legislativo veio a resultar na subscrição de um relatório pelo então Deputado Nelson Marchesan ${ }^{12}$, caracteristicamente um Substitutivo ao primeiro PL (que passou a ser cognominado Substitutivo Marchesan) que, mais tarde, após novas discussões e emendas, veio a dar lugar a uma nova versão. Em função da aprovação, em abril de 2000, de um Requerimento de Urgência ao Projeto de PNE, este segundo Substitutivo foi diretamente dirigido ao plenário da Câmara dos Deputados, deixando de tramitar nas comissões pertinentes, quando, após amplos debates, agora envolvendo especialistas e dirigentes de entidades educacionais, veio a ser alterado por mais duas emendas e, por fim, encaminhado ao Senado Federal. Nesta casa, em 12 de dezembro de 2000, o texto da Câmara dos Deputados obteve aprovação na íntegra pela Comissão de Educação e, logo em seguida, no dia 14, foi aprovado pelo Plenário do Senado, sendo encaminhando para sanção do presidente da República (OLIVEIRA, 2005, 2009; DIDONET, 2000).

Para Valente e Romano (2002, p. 99, grifos no original), em que pesem algumas pequenas modificações, o Substitutivo Marchesan veio a tornar-se texto-base da lei do PNE, apresentando conteúdo peculiar: "ele é um escrito teatrólogo (espécie de Frankenstein) que simula diálogo com as teses geradas pela mobilização social (sobretudo no diagnóstico da situação educacional), mas adota a política do Governo FHC [Fernando Henrique Cardoso] nas diretrizes, nos objetivos e nas metas".

Ainda com base nesses autores, o plano aprovado no Congresso apresentaria também "generalismos" (VALENTE; ROMANO, 2002, p. 100, grifo do original) na ausência de definição de prazos e meios relacionados às suas metas, enquanto que também "detalhismos" [grifo no original] (id.), assim como retrocessos em relação ao que fora disposto no art. 214 da CF/1988 (BRASIL, 1988), na medida em que não faz referência à erradicação do analfabetismo, e substitui expressões como "universalizar o atendimento escolar" (VALENTE; ROMANO, 2002, p. 99) por "elevar de modo global o nível de escolaridade da população" (id.) e, ainda, "melhorar a qualidade do ensino" (id.) por "melhoria da qualidade do ensino em todos os níveis" (id.). Em síntese, o substitutivo aprovado no Congresso acabou por consagrar "como 'plano"

\footnotetext{
11 Oliveira (2009, p. 5) esclarece que "Sob a apreciação da Comissão de Educação Cultura e Desporto (CECD), os PLS foram objeto de 205 emendas [...], apresentadas por onze parlamentares, a maioria do próprio PT [Partido dos Trabalhadores], com o propósito de introduzir, na sua maioria, modificações no projeto do Executivo. Na primeira fase de tramitação na CECD, foram apresentadas 45 emendas aos projetos, 37 delas ainda na $50^{\mathrm{a}}$ legislatura. $O$ parecer emitido pelo Relator, com substitutivo, numa segunda fase, recebeu outras 160 emendas, objeto de nova análise e outro substitutivo revisado e, agora, aprovado pela CECD, que acolheu total ou parcialmente $45,3 \%$ das emendas apresentadas, rejeitando as demais. O grande volume de emendas, entretanto, não representa necessariamente envolvimento de número significativo de parlamentares na Câmara dos Deputados com a matéria, já que o conjunto de seus autores não representa nem 3\% dos membros daquela Casa".
}

12 Partido da Social Democracia Brasileira / Rio Grande do Sul (PSDB/RS). 
a política educacional já praticada pelo MEC" (ibid., p. 104), não contemplando, portanto, "as propostas e reivindicações dos setores democráticos e populares da sociedade" (ibid., p. 106) e, ao invés de constituir um Sistema Nacional de Educação, o substituiu por um Sistema Nacional de Avaliação, expressão do centralismo da gestão da educação nacional então em curso (DOURADO, 2010; PERONI; FLORES, 2014; VALENTE, 2001; VALENTE; ROMANO, 2002).

Ainda assim, segundo Valente e Romano (2002) e Valente (2001), por pressões sociais diversas, especialmente por parte dos educadores, o texto do PNE votado no parlamento veio a considerar algumas importantes medidas, mas que, na sua quase totalidade, viriam a ser vetadas pelo Governo Federal.

\subsection{Aprovação pelo Poder Executivo}

Após cumprido o trâmite relativo à esfera do Poder Legislativo, a então Lei do PNE seguiu para sansão presidencial, vindo a receber nove vetos - Educação Infantil (item 1.3, subitem 22); Magistério da Educação Básica/Formação dos Professores e Valorização do Magistério (item 10.3, subitem 4), Financiamento e Gestão (item 11.3.1, subitens 1, 7 e 13) e, por fim, quatro negativas relacionadas diretamente ao Ensino Superior (item 4.3, subitem 2 e item 4.4, subitens 24. 26 e 29) (OLIVEIRA JÚNIOR; BERALDO, 2003; VALENTE, 2001; VALENTE; ROMANO, 2002). No seu conjunto, os vetos em questão acarretaram importantes restrições à gestão e ao financiamento da educação no País, em especial no âmbito do Ensino Superior (OLIVEIRA JÚNIOR; BERALDO, 2003), produzindo "interpenetração entre as esferas pública e privada sob a égide do mercado, o que, na prática, abriu espaços para a consolidação de novas formas de privatização da educação, sobretudo da educação superior" (DOURADO, 2010, p. 684).

Em que pese o fato desses vetos terem sido "justificados um a um por contrariarem a Lei de Responsabilidade Fiscal ou o interesse público, por não guardarem consonância com o texto constitucional que determina que programas nacionais, regionais e setoriais sejam elaborados de acordo com o Plano Plurianual - PPA e com a Lei Orçamentária anual” (MENDONÇA, 2002, p. 38), Oliveira (2009, p. 12) esclarece que, em nota técnica conjunta com vistas à análise dos vetos interpostos pelo Executivo ao PNE, as consultorias de Orçamento e Fiscalização Financeira, da Câmara dos Deputados, e de Orçamento, Fiscalização e Controle, do Senado Federal, consideraram inconsistentes todos os argumentos apresentados para fundamentar tais vetos.

A um só tempo, cabe destacar que a própria presidência da República, ao enviar a Mensagem $\mathrm{n}^{\circ} 9$, de 9 de janeiro de 2001, na qual comunica os seus vetos ao 
parlamento, "confessa que sua posição ante a matéria foi ditada pela área econômica do governo e não pelos seus auxiliares e organismos diretamente responsáveis pela educação" (VALENTE; ROMANO, 2002, p. 105), o que, de um modo ou de outro, acaba por sinalizar, por um lado, a falta de vontade política de o governo federal adequar as metas econômicas do país às demandas educacionais do plano (MENDONÇA, 2002) e, por outro, as influências das políticas do Fundo Monetário Nacional (FMI) ao País (VALENTE; ROMANO, 2002). Em consequência, o PNE 2001-2010 veio a expor grande inconsistência, pois, embora previsse metas voltadas à expansão de todos os níveis e modalidades de ensino no País, não presumiu custos e tampouco fontes de recursos adicionais para financiá-las (DAVIES, 2014).

Finalmente, o PNE 2001-2010 foi sancionado pela presidência da República em 9 de janeiro de 2001 - Lei n ${ }^{\circ}$ 10.172/2001 (BRASIL, 2001) - determinando, entre outros aspectos, o estabelecimento de vinculações em relação aos planos infranacionais nos termos de que, a partir de sua vigência, os estados, o Distrito Federal e os municípios deveriam "[...] elaborar planos decenais correspondentes" (BRASIL, 2001, art. $2^{\circ}$ ), coerentemente ao previsto na CF/1988 (BRASIL, 1988, arts. 211 e 214) ${ }^{13}$ e na LDBEN n ${ }^{\circ}$ 9.394/1996 (BRASIL, 1996, art. $2^{\circ} \mathrm{e}$ art. 10, III).

\section{Elaboração dos PEEs}

Conforme mencionado na introdução deste artigo, em 2014, somente 12 (46\%) estados da federação expunham PEEs aprovados por lei. Em 2010, havia estados que, embora não possuíssem PEEs, sinalizaram estar se ocupando de sua construção (Acre, Amapá, Ceará, Piauí e Sergipe), e outro que havia indicado ter principiado sua elaboração, mais adiante, em 2013, agora sob expectativa de aprovação do novo PNE (Maranhão). Contudo, até o mês de abril de 2014 não se logrou êxito na localização, via internet, desses planos, assim como de informações sobre eventuais trâmites legislativos que porventura tenham cumprido e, tampouco, das leis que poderiam estar regulamentando-os, situação que igualmente se repete para os estados do Espírito Santo, Rondônia e Rio Grande do Norte. Outros estados, embora tivessem elaborado os seus respectivos PEEs com base no PNE 2001-2010, não vieram a tê-los abonados pelo Poder Legislativo local ou mesmo na esfera do Poder Executivo, como no caso do Paraná, do Rio Grande do Sul e de São Paulo, em que a Assembleia Legislativa não os aprovou; de Roraima, cujo PEE veio a ser recusado pelo Conselho Estadual de Educação (CEE) e, ainda, de Santa Catarina, cujo plano foi considerado inviável pela Casa Civil ${ }^{14}$.

${ }^{13}$ Vale a ressalva de que a CF/1988 se refere ao PNE como um plano de duração plurianual, redação alterada para "duração decenal" pela Emenda Constitucional (EC) n 59, de 11 de novembro de 2009 (BRASIL, 2009).

${ }^{14}$ Além dessas unidades federativas, cabe destacar que o Distrito Federal não possui plano de educação, embora o Fórum de Educação do Distrito Federal (FED) tenha definido, em fevereiro de 2013, cronograma inicial de sua preparação (Federação de Sindicatos de Professores de Instituições Federais de Ensino Superior - PROIFES. 
No que remete aos estados que em abril de 2014 possuíam PEEs, os dados do Quadro 2 revelam que, se por um lado, alguns desses planos foram pioneiramente aprovados - Pernambuco e Mato Grosso do Sul-, outros o fizeram já quase ao final do prazo de vigência do PNE 2001-2010, a citar, o Rio de Janeiro e o Pará. Em meio a este contexto, convém observar que, pelo fato de o PEE de Minas Gerais ter sido aprovado posteriormente ao término da vigência do PNE 2001-2010, ou seja, em data situada fora do escopo temporal deste estudo, as análises aqui realizadas não o contemplam ${ }^{15}$.

Quadro 2. Enquadramento legal dos PEEs analisados.

\begin{tabular}{|l|c|c|c|c|}
\hline Estado / Referência & Lei $\mathbf{n}^{\mathbf{0}}$ & Data de aprovação & Período & $\begin{array}{c}\text { Duração } \\
\text { (em anos) }\end{array}$ \\
\hline Alagoas (2006a; 2006b) & 6.757 & 03 de agosto de 2006 & $2006-2015^{(2)}$ & 10 \\
\hline Amazonas (2008a; 2008b) & 3.268 & 07 de julho de 2008 & $2008-2017^{(3)}$ & 10 \\
\hline Bahia (2006a; 2006b) & 10.330 & 15 de setembro de 2006 & $2006-2015^{(3)}$ & 10 \\
\hline Goiás (2008a; 2008b) & $62^{(1)}$ & 09 de outubro de 2008 & $2008-2017^{(2)}$ & 10 \\
\hline Mato Grosso (2008a; 2008b) & 8.806 & 10 de janeiro de 2008 & $2008-2017^{(3)}$ & 10 \\
\hline $\begin{array}{l}\text { Mato Grosso do Sul } \\
\text { (2003a; 2003b) }\end{array}$ & 2.791 & 30 de dezembro de 2003 & $2003-2010^{(2)}$ & 08 \\
\hline Minas Gerais (2011) & 19.481 & 12 de janeiro de 2011 & $2011-2020^{(2)}$ & 10 \\
\hline Pará (2010) & 7.441 & 02 de julho de 2010 & $2010-2019^{(3)}$ & 10 \\
\hline Paraíba (2006a; 2006b) & 8.043 & 30 de junho de 2006 & $2006-2015^{(3)}$ & 10 \\
\hline Pernambuco (2002) & 12.252 & 08 de julho de 2002 & $2002-2011^{(3)}$ & 10 \\
\hline Rio de Janeiro (2009a; 2009b) & 5.597 & 18 de dezembro de 2009 & $2009-2018^{(4)}$ & 10 \\
\hline Tocantins (2007a; 2007b) & 1.859 & 06 de dezembro de 2007 & $2006-2015^{(2)}$ & 10 \\
\hline
\end{tabular}

FONTE: Os autores (2014).

(1) Lei Complementar.

(2) Período explicitado no documento do PEE e/ou na lei correspondente.

(3) Período não explicitado no PEE e na lei correspondente, deduzido a partir da sua data de aprovação e do tempo de duração indicados.

(4) Período não explicitado no PEE e na lei correspondente, deduzido a partir da sua data de publicação e do tempo de duração inferido por meio na análise estabelecida para suas metas.

Fórum inicial elaboração do Plano Distrital de Educação. Brasília, DF, 2014. Disponível em: <http://proifes.org. br/noticia/876/forum-inicia-elaboracao-do-plano-distrital-de-educacao>. Acesso em: 11 abr. 2014.).

${ }^{15}$ Cabe ainda sinalizar que nem todos os PEEs e/ou suas respectivas leis indicam explicitamente o período de abrangência do plano, sendo recorrente a sinalização, apenas, da sua duração, a exemplo do que acontece com o PNE 2001-2010 cujo art. $1^{\circ}$ indica que corresponde a um plano de dez anos (BRASIL, 2001). Especificamente nestes casos, os períodos registrados no Quadro 2 foram deduzidos tomando por base a data de aprovação do PEE e a do início da sua vigência (devidamente explicitado na lei), em paralelo à consideração do tempo de duração do plano. 
Em observância ao PNE 2001-2010, esses PEEs são, igualmente, decenais, à exceção do plano do Mato Grosso do Sul que, abarcando o período 2003-2010, consiste em um plano de oito anos. Importante salientar que, do conjunto de planos em tela, apenas o de Mato Grosso do Sul e de Pernambuco não mais se encontravam, em 2014, em vigência: o primeiro tendo expirado em 2010, e, o segundo, em 2011. No caso de Pernambuco, em novembro de 2012, por época do lançamento oficial da Conferência Estadual de Educação, foram iniciadas as discussões para a construção de um novo plano ${ }^{16}$.

\subsection{Atores envolvidos}

A análise dos PEEs aprovados ao longo do período de vigência do PNE 2001-2010 (BRASIL, 2001) permitiu observar que todos, sem exceção, apresentam alguma preocupação em registrar nesses documentos que se constituíram resultado de debate com a sociedade civil, tendo envolvido múltiplos atores sociais, alguns com maior clareza e objetividade, enquanto que outros de modo impreciso e, em alguns casos, vago - o que, em função das delimitações metodológicas da pesquisa realizada não permite comprovação -, conforme se pode constatar por meio dos excertos apresentados no Quadro 3. Todavia, constata-se que o PEE do estado do Amazonas é aquele que melhor explicita os segmentos da sociedade local representados no processo de elaboração do plano, enquanto que os demais estados indicam, genericamente, a realização de consultas à sociedade, a ocorrência de participações e discussões democráticas e a promoção de amplos debates.

\section{Quadro 3. Participações no processo de elaboração dos PEEs}

\begin{tabular}{|c|c|}
\hline Estado & PEE (excertos) \\
\hline $\mathrm{AL}$ & $\begin{array}{l}\text { "[...] este PEE/AL, embora elaborado mediante a coordenação governamental, é } \\
\text { produto de consultas diretas e sistemáticas à sociedade, como se pode observar } \\
\text { pelas instituições, entidades e organizações }{ }^{(1)} \text { envolvidas em cada sub-comitê } \\
\text { temático e pelo fato de ter passado por uma discussão ampliada via II CECEAL (2). } \\
\text { [...] este Plano resulta da maior audiência popular que foi possível ao Comitê Gestor } \\
\text { promover junto aos setores que, em Alagoas, direta ou indiretamente, tinham a ver } \\
\text { com a educação" (ALAGOAS, 2006a, p. 11). }\end{array}$ \\
\hline AM & $\begin{array}{l}\text { "A construção coletiva do Plano Estadual de Educação - PEE/AM( }{ }^{(3)} \text { representa um } \\
\text { marco na História da Educação no Estado do Amazonas, mais e, principalmente, } \\
\text { por ter tido a participação efetiva da sociedade civil organizada, dos sindicatos, de } \\
\text { órgãos que lidam com o processo formal e informal de educação, de representação } \\
\text { dos povos indígenas, de pais e alunos, em todas as dependências administrativas, } \\
\text { no âmbito do Estado [...]" (AMAZONAS, 2008b, p. 13). }\end{array}$ \\
\hline
\end{tabular}

Continua

${ }^{16}$ FÓRUM NACIONAL DE EDUCAÇÃO. Pernambuco realiza lançamento oficial da Conferência Estadual de Educação. Brasília, DF: Ministério da Educação, 2014. Disponível em: <http://fne.mec.gov.br/index.php/noticias/134pernambuco-realiza-lancamento-oficial-da-conferencia-estadual-de-educacao >. Acesso em: 12 abr. 2014. 
Continuação

\begin{tabular}{|c|c|}
\hline BA & $\begin{array}{l}\text { "Este Plano de caráter estadual, discutido democraticamente pelos diversos } \\
\text { segmentos da sociedade baiana, pensa, ao ampliar o conceito da cultura, em uma } \\
\text { escola efetivamente democrática para todos. [...] Essa metodologia subsidiou a } \\
\text { definição de um plano(4) plural efetivamente construído pela sociedade baiana" } \\
\text { (BAHIA, 2006b, p. 3). }\end{array}$ \\
\hline GO & $\begin{array}{l}\text { "Assim, este Plano Estadual(5), que ora conseguimos apresentar à sociedade, } \\
\text { reveste-se de grande significado histórico, por ser o primeiro do gênero e por ser } \\
\text { o resultado de um amplo e democrático debate com a sociedade civil organizada e } \\
\text { com os segmentos que compõem a educação no Estado" (GOIÁS, 2008b, p. 14). }\end{array}$ \\
\hline MT & $\begin{array}{l}\text { "O processo de elaboração do plano se pautou no princípio constitucional } \\
\text { de gestão democrática do ensino público, [...] qarantiu, com isso, o processo } \\
\text { democrático de participação de todos os atores que, de uma forma ou de outra, } \\
\text { têm a ver com a educação, ou seja, o Poder Executivo, o Poder Legislativo, o } \\
\text { Poder Judiciário, o Ministério Público e a Sociedade Civil Organizada" (MATO } \\
\text { GROSSO, 2008b, p. 6). }\end{array}$ \\
\hline MS & $\begin{array}{l}\text { "[Contando com parcerias] [...] a Secretaria de Estado de Educação deflagrou } \\
\text { um amplo movimento de discussão com a população, de forma participativa e } \\
\text { representativa, envolvendo todos os segmentos }{ }^{(6)} \text { ligados direta ou indiretamente } \\
\text { com a educação no Estado, para construir, coletivamente, um Plano de Educação } \\
\text { que representasse, com legitimidade, os anseios e necessidades da população" } \\
\text { (MATO GROSSO DO SUL, 2003b, p. 8). }\end{array}$ \\
\hline PA & $\begin{array}{l}\text { "[A construção do PEE/PA se deu no âmbito da] I Conferência Estadual de } \\
\text { Educação [a qual] traduz o amplo processo democrático que prevaleceu desde a } \\
\text { realização das plenárias e conferências municipais e nas conferências regionais que } \\
\text { culminaram com a reunião estadual. [...] O total de pessoas envolvidas ultrapassa } \\
70 \text { mil pessoas, entre trabalhadores e trabalhadoras da educação, gestores, } \\
\text { pais, alunos, responsáveis, lideranças dos movimentos sociais organizados, } \\
\text { parlamentares e representantes de instituições, entidades, organizações } \\
\text { governamentais e não- governamentais" (PARÁ, 2010b, p. 1). }\end{array}$ \\
\hline PB & $\begin{array}{l}\text { "A elaboração do Plano, de forma participativa e democrática, inclusive na definição, } \\
\text { coletiva, das prioridades para a educação no Estado da Paraíba, considera a } \\
\text { mobilização social como garantia da legitimidade e da eficácia das ações a serem } \\
\text { realizadas" (PARAÍBA, 2006b, p. 14). }\end{array}$ \\
\hline PE & $\begin{array}{l}\text { "Este Plano Estadual contém programas, diagnósticos, diretrizes, objetivos e } \\
\text { metas que integram e consolidam as políticas nacionais, com um diferencial } \\
\text { específico do Estado de Pernambuco: a participação e o apoio da sociedade na } \\
\text { construção de suas propostas, delineadas durante a construção desse processo" } \\
\text { (PERNAMBUCO, 2002b, p. 10). }\end{array}$ \\
\hline RJ & $\begin{array}{l}\text { "O texto-base [...] continha uma proposta de Minuta do Plano Estadual de } \\
\text { Educação, resultante de inúmeros debates no âmbito das Coordenadorias Regionais } \\
\text { da SEEDUC, dos municípios fluminenses, por intermédio da UNDIME-RJ, além de } \\
\text { dois seminários internos realizados na SEEDUC. Esse documento foi rediscutido } \\
\text { durante os Fóruns Regionais, [...] tendo sido apreciado e votado durante o II } \\
\text { Congresso Estadual de Educação [...] (RIO DE JANEIRO, 2010b, p. 65). }\end{array}$ \\
\hline
\end{tabular}

Continua 
Continuação

\begin{tabular}{|l|l|}
\hline TO & "Os encaminhamentos dados pela Secretaria da Educação e Cultura para a \\
& elaboração deste Plano Estadual de Educação asseguraram a participação \\
& representativa da comunidade escolar e dos diversos segmentos da sociedade \\
que, de uma forma ou de outra, estão ligados ao Sistema Educacional. Este Plano \\
é o resultado de ampla discussão [...] A sua legitimidade está referendada por esse \\
trabalho de elaboração coletiva e pela aprovação da Assembléia Legislativa do \\
Estado do Tocantins" (TOCANTINS, 2007b, p. 1).
\end{tabular}

Fonte: Os autores (2014).Notas: Alagoas (AL), Amazonas (AM), Bahia (BA), Goiás (GO), Mato Grosso (MT), Mato grosso do Sul (MS), Pará (PA), Paraíba (PB), Pernambuco (PE), Rio de Janeiro (RJ), Tocantins (TO).

(1) O PEE/AL lista 35 instituições, entidades e organizações que participaram na sua formulação (ALAGOAS, 2006a);

(2) II Congresso Constituinte Escolar;

(3) Afora evidenciar, de modo geral, a participação dos Centros Municipais de Educação Infantil, das escolas estaduais, municipais e particulares, o PEE/AM lista 77 "instituições parceiras" (AMAZONAS, 2008b, p. 11-12);

(4) O PEE/BA não lista as instituições, entidades e organizações que participaram de sua construção; todavia informa que contou com a participação de "aproximadamente 2.000 pessoas" (BAHIA, 2006b, p. 3);

(5) Além das representações de oito Secretarias Municipais de Educação (SMEs), o PEE/GO destaca a participação de 17 "'órgãos/entidades" no processo que culminou com a elaboração do Plano (GOIÁS, 2008b, p. 5-6);

(6) Afora listar cinco "parcerias" que se associaram à SEEDUC com vistas à sua elaboração,

o PEE/MS contém um fluxograma que evidencia o fluxo de ações associado ao seu processo de elaboração coletiva, que contou, entre outros, com oficinas regionais as quais envolveram os 77 municípios do Estado (MATO GROSSO DO SUL, 2003b).

Afora indicar para a preocupação em destacar que o documento resulta da construção de um amplo processo de participação - o qual, conforme anteriormente observado, não se constituiu realidade do processo que envolveu o PL encaminhado pelo Poder Executivo federal e cujas determinações, em grande parte, foram contempladas no PNE 2001-2010 -, a análise dos PEEs permite também observar que foram adotadas três estratégias de divulgação das instituições, entidades e organizações envolvidas no seu processo elaboração: (i) listagem sequencial nas páginas iniciais do plano propriamente dito, caso dos PEEs de Alagoas e do Amazonas; (ii) apresentação no interior do texto do documento (em especial na seção correspondente à introdução), situação do PEE da Paraíba, ou (iii) conjunção dessas duas possibilidades, caso dos PEEs de Goiás e do Mato Grosso do Sul ${ }^{17}$.

17 Não se identificou, nos documentos relativos aos PEEs da Bahia (2006a; 2006b), do Mato Grosso (2008a; 2008b), do Pará (2010) e do Tocantins (2007a; 2007b), informações quanto às instituições, entidades e organizações envolvidas no processo de discussão e elaboração, em que pese o fato de apresentarem, a exemplo dos demais planos, os responsáveis pela coordenação desse processo. 
Além disso, no que tange aos atores envolvidos no processo de elaboração dos PEEs faz-se importante destacar algumas recorrências, além das Secretarias de Estado de Educação, do CNE e do Fórum Estadual de Educação (FEE), principais responsáveis pela coordenação de todo o processo de elaboração dos planos aqui analisados, citam-se, a União Nacional dos Dirigentes Municipais de Educação (UNDIME) - em Alagoas, Amazonas, Goiás, Mato Grosso, Mato Grosso do Sul e Paraíba -; as universidades públicas - Alagoas, Amazonas, Goiás, Mato Grosso do Sul e Paraíba -; o(s) sindicato(s) de professores e/ou de trabalhadores em educação - Alagoas, Amazonas, Goiás, Mato Grosso e Paraíba -; a União Nacional dos Conselhos Municipais de Educação (UNCME) - em Alagoas, Goiás e Paraíba; o Ministério Público (MP) - em Alagoas, Mato Grosso e na Paraíba -; e, ainda, a Comissão de Educação da Assembleia Legislativa - Goiás, Mato Grosso e Rio de Janeiro.

Foi também possível identificar número significativo de especificidades regionais em relação às instituições, entidades e organizações envolvidas no processo de elaboração desses PEEs. Sem deixar de valorizar a totalidade de seu conjunto, apenas a título de exemplificação, citamos o Movimento Estudantil Indígena da Amazônia (MEIAM) e o Serviço de Cooperação com o povo Yanomami (SECOYA), ambos listados no PEE do Amazonas.

\subsection{Início e término do processo}

A observação dos PEEs alvos deste estudo permite constatar ainda que grande parte não contém informações que balizem deduções precisas quanto às datas de início e de término do seu processo de elaboração, esta entendida como aquela em que a proposta final de PEE foi, de fato, encaminhada ao governo do estado correspondente. Apenas quatro planos apresentam claramente o ano em que foi dado início à sua elaboração, nos termos da realização das discussões iniciais: Alagoas, em 2003; Amazonas, também em 2003; Goiás, em 2002 e Paraíba, em 2001, cabendo destacar que este último, embora pioneiro, pois principiou a elaboração do plano logo após a aprovação do PNE 2001-2010, veio tê-lo aprovado pela Assembleia Legislativa cerca de cinco anos após, em junho de 2006. Sob esta perspectiva, se considerarmos os anos em que os PEEs de Alagoas, Amazonas e Goiás foram aprovados, o primeiro, em 2006, enquanto que os dois últimos, em 2008, percebemos que vem se constituindo longo o processo que envolve a elaboração e aprovação dos PEEs, esbarrando, especialmente, em dificuldades associadas à própria Secretaria de Estado de Educação (SEDUC) e/ou ao trâmite na Casa Legislativa do Estado, fato que nos remete ao novo PNE (BRASIL, 2014), cuja tramitação no Congresso Nacional principiou em dezembro de 2010, terminando apenas em junho de 2014. 
Considerando os quatro planos em questão, contabiliza-se que o tempo médio decorrido entre o início das discussões e sua aprovação na Casa legislativa correspondente foi de 4,8 anos, o que leva à indagação sobre quais fatores constituem-se os principais responsáveis por tamanha morosidade que, em última análise, chega a comprometer a adequação dos dados do plano à realidade da educação do estado, em constante movimento.

\subsection{Coordenação do processo}

Apesar de não haver lei federal que associe a responsabilidade pela coordenação do processo de elaboração dos planos de educação subnacionais a um determinado órgão público em específico, os CEEs e os Conselhos Municipais de Educação (CMEs), em função de suas competências normativas e/ou consultivas, despontam, ao lado das SEDUCs e Secretarias Municipais de Educação (SMEs), como órgãos privilegiados para esta finalidade. Sobre a elaboração dos PMEs, Monlevade (2004, p. 40), sinaliza que "O papel de dar o comando, de coordenar a elaboração, de executar as ações necessárias" à sua construção e posterior execução e avaliação é da SME, "mas, havendo um Conselho Municipal de Educação, com poder normativo ou somente consultivo, é dele o papel primordial de inspirar, incentivar, cobrar e orientar todo o processo de elaboração, execução e avaliação" do plano (id.), assertiva que se entende igualmente válida para o caso dos PEEs, ou seja, o ator central desse processo passa a constituir-se o CEE, mas sob liderança da SEDUC.

Assim, foi possível perceber por meio dos PEEs investigados que a coordenação ${ }^{18}$ do processo de elaboração dos planos se fez associar, prioritariamente, ao CEE, caso do Amazonas e Paraíba; à SEDUC, a citar, Alagoas, Bahia, Goiás, Mato Grosso do Sul, Pará, Rio de Janeiro e Tocantins; e, por vezes, ao FEE, naqueles estados que, à época, o haviam constituído, como o Mato Grosso e a Paraíba.

No caso específico da Paraíba, convém distinguir que o processo de elaboração se deu em dois momentos: o primeiro sob a responsabilidade do CEE, órgão que pela Constituição deste estado é o responsável, "em primeira instância", por sua elaboração (PARAÍBA, 2006b, p. 12), enquanto que, o segundo, iniciado em 2003, coordenado pelo FEE, decorreu de entendimentos da nova administração estadual com o CEE, com vistas à ampliação do debate "com novos parceiros, novos temas e nova estratégia de discussão" (id.). Tal fato poderia sugerir uma aparente concorrência da responsabilidade

18 Tendo como referência exclusivamente o PEE de Pernambuco (2002), não foi possível detectar a responsabilidade associada à sua coordenação. 
legal para com a elaboração do PEE, entre o CEE e o FEE, cabendo destacar, portanto, que a ordenação constitucional se sobrepõe aos demais atos legislativos. Além disso, é importante observar que a SEDUC, mesmo não tendo sido responsável pela coordenação do processo que culminaria com a aprovação do PEE, parece ter composto importante parceria com as coordenações, especialmente no sentido de viabilizar as condições para a consecução da proposta do plano, parceria esta que não se restringiu ao processo de elaboração do PEE da Paraíba, mas se fez notar nos demais contextos relativos aos PEEs aqui analisados.

\subsection{Formas e estratégias de efetivação}

Entendida como expressão democrática e democratizante da educação (CURY, 2005), a gestão democrática passou a integrar os principais ordenamentos jurídicos e normativos associados à educação brasileira. Sendo assim, tanto a CF/1988 (BRASIL, 1988) quanto a LDBEN no 9.394/1996 (BRASIL, 1996) a incorporaram como princípio norteador do ensino público, devendo ser destacado o fato de o PNE 2001-2010 (BRASIL, 2001) ter determinado que no exercício de sua autonomia, cada sistema de ensino há de implantar gestão democrática, a qual deve considerar como um de seus eixos estruturantes a participação da comunidade.

É possível afirmar que a apreensão de que o processo que culminaria com a elaboração de um plano de educação para o estado deveria ocorrer sob a égide da gestão democrática contribuiu para que, na busca tanto por contemplar o maior índice de participação possível quanto por otimizar recursos, alguns estados optassem por agregar as discussões a respeito de sua proposta de PEE a eventos de grande amplitude, caso, por exemplo: (i) do Pará, cuja I Conferência Estadual de Educação contou com a "dupla finalidade" de consolidar as proposições do Estado para a I Conferência Nacional de Educação Básica (CONEB), bem como construir o seu PEE (PARÁ, 2010b, p. 1); e (ii) de Alagoas, que contou com o último dia do II Congresso Constituinte Escolar para "fechar as discussões [sobre a proposta do PEE/AL] que já tinham acontecido na base, através das jornadas preparatórias do Congresso" (ALAGOAS, 2006b, p. 10). Convém ressair ainda que, se no caso de Alagoas o projeto do PEE foi apreciado durante a realização do II Congresso Constituinte Escolar (ALAGOAS, 2006b), no Mato Grosso do Sul a Constituinte Escolar deu início à sua discussão (MATO GROSSO DO SUL, 2003b). Evidencia-se também os casos do Mato Grosso, cujo fechamento das discussões sobre o seu PEE se deu em meio a um evento específico, qual seja, a $1^{\text {a }}$ Conferência do Plano Estadual de Educação (MATO GROSSO, 2008b), bem como o do Rio de Janeiro cuja proposta de PEE foi 
apreciada e votada durante a realização do II Congresso Estadual de Educação, previsto para ocorrer a cada dois anos, o qual tem como objetivo "fomentar a participação de diferentes atores da sociedade civil fluminense na elaboração da política educacional do estado e traduzir os elementos essenciais do Plano Nacional de Educação na construção do Plano Estadual de Educação" (RIO DE JANEIRO, 2009b, p. 66).

Do ponto de vista das estratégias empregadas para a consecução do processo de elaboração dos PEEs, a análise dos planos em tela permite perceber que se desenvolveu basicamente sob duas estratégias metodológicas, em que pese o fato de nem todos os planos terem detalhado este processo de modo satisfatório, descrevendo-o, portanto, de forma lacunar e/ou pouco clara. A primeira contou com a organização de uma comissão/comitê - que em alguns casos veio a constituir (sub)grupos temáticos, em geral, integrados por ampla representação - responsável pela elaboração da versão inicial da proposta de plano, a qual pode ou não ter seguido para discussão da comunidade escolar, em particular, e da sociedade civil, de modo mais amplo, isto por meio da realização de reuniões, seminários, congressos, entre outros eventos (veja-se Quadro 3), visando, posteriormente, a incorporar possíveis sugestões à proposta inicial, antes de vir a ser encaminhada à Assembleia Legislativa do Estado $^{19}$ (cf. ALAGOAS, 2006b; AMAZONAS, 2008b; PARAÍBA, 2006b; RIO DE JANEIRO, 2009b).

Já sob a perspectiva da segunda estratégia, a comissão/comitê - que em alguns casos também veio a constituir (sub) grupos temáticos necessariamente integrados por ampla representação - foi responsável pela consolidação da proposta de plano. Neste sentido, a comissão/comitê teve por objetivo receber, agregar, organizar, analisar e propor uma versão inicial para o plano que tivesse por base as propostas e sugestões que lhe foram encaminhadas e que resultaram da participação da comunidade escolar e dos diversos segmentos da sociedade civil (cf. GOIÁS, 2008b; MATO GROSSO, 2008b; MATO GROSSO DO SUL, 2003b).

\footnotetext{
${ }^{19}$ Analogamente, e guardadas as devidas proporções, o processo que culminou com a aprovação do novo PNE (BRASIL, 2014) apresenta aproximações com a primeira estratégia em questão, uma vez que partiu da elaboração de um "Documento-Referência", construído no âmbito do Fórum Nacional de Educação (FNE), e culminou com a elaboração de um "Documento Final", resultado das proposições apresentadas no âmbito da Conferência Nacional de Educação (CONAE, 2014), o qual deveria se constituir "horizonte para a formulação e materialização de políticas de Estado na educação, sobretudo, para a construção do novo Plano Nacional de Educação, período 2011-2020" (BRASIL, [s.d.], p. 9), e do qual, a exemplo do que ocorreu com o PNE 2001-2010 (BRASIL, 2001), o Poder Executivo federal em muito se afastou por ocasião da elaboração do PL n 8.035/2010 (BRASIL, 2011).
} 
Reitera-se que, na prática, as duas estratégias direcionadas à consecução do processo de elaboração dos PEEs diferem-se basicamente em relação à autoria da preparação da versão inicial da proposta de plano: se na primeira a comissão elabora a minuta do documento, o qual é posteriormente levado para apreciação da sociedade; na segunda, a comissão é responsável por agregar em um único documento as propostas advindas de diferentes setores, o qual já nasce de um processo de participação social. Ambas as estratégias apresentam potenciais e desafios, cabendo aos envolvidos decidirem por aquela que se torna mais adequada aos seus princípios e possibilidades ${ }^{20}$.

Convém realçar, por fim, que não raras vezes foram observadas dificuldades não só durante o processo de elaboração e aprovação dos PEEs, mas já para dar início ao seu processo de elaboração. Um exemplo emblemático se faz associar ao Plano do Rio de Janeiro, cuja trajetória remete ao ano de 2007, ocasião em que "a Comissão de Educação da ALERJ fez uma representação [contra a SEDUC] junto ao Ministério Público Estadual, para que o Plano fosse apresentado" (RIO DE JANEIRO, 2009b, p. 65), uma vez que neste Estado a SEDUC é responsável pela coordenação da elaboração do PEE, o qual deve contar com "ampla discussão pública com as diferentes representações educacionais" - Lei $\mathrm{n}^{\circ}$ 4.528, de 28 de março de 2005 (RIO DE JANEIRO, 2005, art. 67).

Outro destaque se faz associar ao PEE de Alagoas, o qual permite observar que, no período compreendido de 2002/1 a 2004/2, época em que as entidades começaram a solicitar a elaboração do Plano à Secretaria de Educação de Alagoas até o término de sua discussão, estiveram à frente daquela Secretaria, no mínimo, quatro secretários (ALAGOAS, 2006b). Esta informação revela significativa importância no contexto que envolve a elaboração de plano decenais de educação: Como planejar um plano decenal para a educação em meio à tamanha instabilidade política? Neste sentido, vale observar que o PEE de Alagoas apresenta que "Importa assinalar, a essa altura, que toda a prática de planejamento da educação em Alagoas jamais ultrapassou os limites de uma gestão e, assim mesmo, com o agravante de, na maioria delas, ter esses planos como mera formalidade" (ALAGOAS, 2006b, p. 10).

\footnotetext{
${ }^{20}$ Não foi possível caracterizar os PEEs da Bahia (2006a; 2006b), Pará (2010), Pernambuco (2002) e Tocantins (2007a; 2007b) em um dos dois grupos aqui definidos, haja vista que as análises se encontram restritas aos documentos oficiais - plano e lei aprovada -, os quais, no caso dos estados mencionados, não disponibilizam as informações necessárias ao entendimento do seu processo de discussão e elaboração. Embora esses PEEs, em diferentes momentos, reiterem o importante movimento democrático em prol do envolvimento e participação, especialmente da comunidade escolar e da sociedade de modo geral, são perpassados por lacunas no que tange à explicitação da operacionalização de sua construção.
} 


\section{Aprovação e disseminação dos PEEs}

Uma importante etapa da elaboração de um plano de educação consiste, ao final da realização do diagnóstico ${ }^{21}$, na definição das diretrizes ${ }^{22}$ e dos objetivos e metas ${ }^{23}$, em proceder-se à avaliação do seu potencial em vir a dar respostas satisfatórias às suas prioridades e em produzir os efeitos esperados, assim como constatar-se a sua exequibilidade, ou seja, a sua viabilidade de execução. Somente após esta última etapa de construção do plano - que, na prática, constitui-se em uma avaliação a priori de sua aprovação - é que se recomenda o seu encaminhamento para o órgão do Poder Legislativo responsável pela sua aprovação e regulamentação (BONAMINO et al., 2006).

Assim, o plano deve ser avaliado a partir de indicadores como: (i) clareza quanto à explicitação dos eixos da política educacional, diretrizes, objetivos e metas, alternativas de ação, custos e sistemática de acompanhamento e avaliação de sua execução; (ii) precisão dos objetivos e metas no sentido de permitirem mensurações ao longo do processo futuro de acompanhamento e avaliação; (iii) correspondência com a realidade política, técnica, legal e financeira que o condicionam; entre outros aspectos (BONAMINO et al., 2006).

Considerando que a avaliação preliminar do plano elaborado não se constitui em uma orientação apenas circunscrita aos PMEs - alvo do documento do MEC aqui tomado por referência (BONAMINO et al., 2006) -, mas em uma demanda igualmente importante para a garantia da efetividade dos PEEs (e de um PNE), constatou-se que nenhum dos planos sob análise mencionou a realização deste tipo de avaliação, ou qualquer outra ação similar que viesse a assegurar o seu potencial e exequibilidade, o que, por si só, os torna frágeis quanto à possibilidade de virem a se constituir com

${ }^{21}$ O diagnóstico consiste no exame da situação de cada eixo temático do plano - relativo aos níveis/etapas de educação e modalidades de ensino, assim como a outros temas específicos -, isto por meio da análise de dados quantitativos e de caracterizações e contextualizações qualitativas, compreendendo a especificação de problemas, dificuldades e perspectivas para uma dada realidade educacional. É, portanto, a partir do diagnóstico que se estabelecem as escolhas para a formulação das políticas correlatas, em termos dos seus princípios e diretrizes, e para a tomada de decisões estratégicas, isto com maior fidedignidade em relação a uma dada realidade educacional (BONAMINO et al., 2006; BRASIL, 2005; MONLEVADE, 2002; ROCHA; MONLEVADE; AGUIAR, 2006).

22 É por intermédio das diretrizes que se explicitam as concepções e princípios relacionados às possíveis soluções, alternativas e estratégias destinadas à solução e superação dos problemas identificados na etapa diagnóstica da elaboração do plano, devendo ainda justificar as opções adotadas e as prioridades assumidas (BONAMINO et al., 2006; BRASIL, 2005; MONLEVADE, 2002).

23 Já os objetivos e metas do plano devem trazer à vista as decisões tomadas acerca do que fora estabelecido nas diretrizes, no sentido de explicitar as intenções e ações das políticas educacionais a serem adotadas para a solução dos problemas identificados em cada eixo temático, com quantitativos e prazos mensuráveis, com indicação das etapas a serem cumpridas ao longo do seu processo de execução (BONAMINO et al., 2006; BRASIL, 2005; MONLEVADE, 2002). 
efetividade. Assim, após o término da elaboração propriamente dita desses PEEs, grosso modo, a versão finalizada seguiu para aprovação na Assembleia Legislativa correspondente.

\subsection{Espaços de aprovação}

O processo que envolve a construção e aprovação de PEEs tem sua terminalidade nas Casas Legislativas dos governos estaduais. Neste sentido, vale observar que alguns dos planos aprovados relacionam sua legitimidade, entre outros, à aprovação na Assembleia Legislativa, caso do Mato Grosso do Sul e de Tocantins, para os quais, identicamente, "A sua legitimidade está referendada por esse trabalho de elaboração coletiva e pela aprovação da Assembleia Legislativa do Estado [...]" (MATO GROSSO DO SUL, 2003b, p. 4; TOCANTINS, 2007b, p. 1).

Sob esta perspectiva, destacamos aqui algumas dificuldades associadas aos espaços de aprovação dos Planos, as quais, no caso dos PEEs investigados, estão vinculadas basicamente, de um lado, à lentidão, e até mesmo à ausência, do envio da proposta de plano pelo Poder Executivo estadual à Assembleia Legislativa e, de outro, à morosidade propriamente dita do processo legislativo. Os PEEs do Rio de Janeiro, Amazonas e Goiás, diferentemente dos demais analisados, acusam estas dificuldades nos respectivos documentos do plano, fato que não implica que estas e/ou outras dificuldades associadas aos espaços de aprovação do plano não tenham sido experienciadas pelos demais estados envolvidos na pesquisa.

A proposta do PEE do Rio de Janeiro, conforme destacado anteriormente, foi encaminhada à Assembleia Legislativa após a Comissão de Educação ter ingressado com uma representação no Ministério Público Estadual (MPE), sendo que o retorno da SEDUC só se deu dois anos após, com o envio da versão preliminar do PEE àquela Comissão (RIO DE JANEIRO, 2009b).

Já o PEE do Amazonas evidencia que o primeiro projeto do seu PEE "foi construído no ano de 2003, e encaminhado à Casa Civil em fevereiro de 2006. Após a análise dos autos foi encaminhado de volta à SEDUC para a atualização dos dados. " (AMAZONAS, 2008b, p. 15). Tendo por referência unicamente o PEE, é possível inferir que a demora no envio do projeto à Casa Civil, por parte da Secretaria de Estado da Educação e Qualidade do Ensino, associada a uma consequente mudança no cenário educacional local, contribuiu para a necessidade de atualização dos dados do diagnóstico e, por conseguinte, das diretrizes, objetivos e metas presentes no plano. 
Por fim, no caso do PEE de Goiás, a necessidade de atualização dos dados foi premida pelo tempo de tramitação do PL junto ao Poder Legislativo Estadual. Neste sentido, segundo o PEE,

considerando a defasagem de algumas abordagens do Plano Estadual de Educação, elaborado em 2003, revisto em 2006, e ainda em tramitação, onze instituições e entidades que compõem o Fórum Estadual de Educação desencadearam, em 2007, o processo de atualização dos dados educacionais, objetivos e metas [...] (GOIÁS, 2008b, p. 12).

Os trabalhos foram finalizados após a realização de uma audiência pública na Assembleia Legislativa do Estado, a qual, entre outros, tinha por objetivo "despertar os parlamentares estaduais para a necessidade, importância e urgência da aprovação do PEE” (GOIÁS, 2008b, p. 13), o que parece ter surtido efeito, tendo em conta que, já no início do ano legislativo de 2008, a matéria foi apresentada para votação em caráter prioritário.

\subsection{Estrutura dos planos aprovados}

Especificamente em relação à organização interna dos eixos temáticos dos PEEs analisados, é possível afirmar, em linhas gerais, que a maioria dos planos investigados seguiu a estrutura do PNE 2001-2010 (BRASIL, 2001), os quais, a partir da realização de um diagnóstico inicial, que toma por base dados censitários, neste caso, relativos ao estado, estabelecem as diretrizes e, na sequência, os objetivos e metas do plano, isto para cada um dos eixos tratados.

A análise evidencia também que, dos onze planos enfocados, apenas o do Pará e o do Rio de Janeiro se afastam do conceito estrutural do PNE 2001-2010, anteriormente discutido. $\mathrm{O}$ documento do PEE do Pará está dividido em duas seções básicas: a primeira apresenta um diagnóstico geral da educação no estado, trabalhando, em paralelo, as informações associadas aos diferentes eixos temáticos do plano, enquanto a segunda, disposta na forma de quadros, apresenta, separadamente, as diretrizes e os objetivos e metas vinculados a cada um de seus eixos (PARÁ, 2010)24. Por sua vez, o PEE do Rio de Janeiro (2009b), na direção

\footnotetext{
${ }^{24}$ A primeira seção principia com algumas considerações gerais acerca dos desafios postos à educação no Brasil, e no Pará, tendo incluída uma análise do desempenho do Sistema Educacional deste Estado. Em seguida, discute aspectos gerais relacionados à problemática do analfabetismo, da função docente, dos estabelecimentos de ensino, da aprovação/reprovação e evasão escolar, também com foco na realidade nacional em geral e, em particular, do Estado do Pará. Aborda também diagnósticos relacionados aos indicadores do Sistema de Avaliação da Educação Básica (SAEB), aos efeitos da política de municipalização do ensino no financiamento educacional do Pará, à educação superior no Estado e sobre as grandes prioridades nacionais e a construção de um pacto estadual pela educação no Pará (PARÁ, 2010).
} 
diametralmente oposta à do Pará, no que tange especificamente à Educação Básica, inicialmente apresenta, em separado, diagnósticos associados a cada uma de suas etapas e modalidades de ensino para, em um segundo momento, dispor, de forma conjunta, seus objetivos e metas. No que tange aos demais eixos temáticos, o plano apresenta, de modo agregado, o diagnóstico e as diretrizes, seguido dos objetivos e metas ${ }^{25}$. Neste sentido, convém observar que, como o PEE do Rio de Janeiro não traz uma apresentação e/ou introdução, torna-se difícil perceber a intencionalidade que perpassa sua disposição estrutural.

Outro ponto a destacar refere-se à ausência efetiva de diagnósticos relativos aos eixos temáticos anteriormente mencionados, embora cada um seja precedido de subseção denominada "Diagnóstico". Não se nota, portanto, um padrão de análise alicerçada na sistematização de dados estatísticos, demográficos, populacionais, educacionais e/ou financeiros, elaborados em âmbito federal ou estadual, que tivessem viabilizado o conhecimento acerca da real situação educacional local e, com isto, subsidiado a definição de metas e estratégias, de fato, coesas ao atendimento das demandas identificadas ${ }^{26}$. No seu lugar, observam-se, em geral, referências a determinados marcos legais federais - incluindo-se dados, informações e proposições do PNE 2001-2010 - e, em alguns casos, estaduais, relacionados a problemas genéricos e de amplitude nacional que marcam a educação no estado, e, ainda, a discussões teóricas que perpassam os desafios clássicos da educação brasileira, especialmente em termos de sua universalização, exprimindo pouca ou nenhuma especificidade local2 ${ }^{27}$.

Do ponto de vista do quantitativo de objetivos e metas dos PEEs em questão, seu exame revela que pouco mais da metade (55\%) desses planos apresenta quantitativo de decisões inferior ao total associado ao PNE 2001-2010 (BRASIL, 2001), ou seja, possui menos do que 295 objetivos e metas estabelecidas, sendo que o Amazonas, Bahia e Paraíba tangenciam este valor, respectivamente com 295, 302 e 309 objetivos e metas, enquanto Alagoas e Mato Grosso o ultrapassa, o primeiro, em 34 decisões (329) e, o segundo, em 90 (485). De um modo ou de outro, cumpre destacar que o total de 295 objetivos e metas deste PNE é passível de ser considerado demasiadamente elevado, o que, de acordo com

\footnotetext{
${ }^{25}$ Vale destacar que todos os eixos temáticos do PEE do Estado de Goiás (2008b) também são constituídos de duas partes: a primeira conjuga o diagnóstico e as diretrizes e, a segunda, os objetivos e metas.

${ }^{26}$ É importante destacar que o art. 50, § 1º da LDBEN n 9.394/1996 (BRASIL, 1996), por meio de nova redação proporcionada pela Lei $n^{\circ}$ 12.796, de 4 de abril de 2013 (BRASIL, 2013), determina que "O poder público, na esfera de sua competência federativa, deverá: I - recensear anualmente as crianças e adolescentes em idade escolar, bem como os jovens e adultos que não concluíram a educação básica".

${ }^{27}$ Pormenorizações acerca dos dados que tipicamente são utilizados para a realização desses diagnósticos podem ser encontrados em documento do MEC que versa sobre orientações para a elaboração de PMEs (BRASIL, 2005).
} 
levantamento do CNE sobre as avaliações deste plano (BRASIL.CNE, 2009), acabaram por pulverizar e fragmentar o conjunto de suas ações, em larga medida contribuindo para a sua não efetividade. Tal constatação, portanto, também serve como indicador dos riscos de impraticabilidade que esses PEEs vieram a expor, especialmente aqueles que chegam a ultrapassar as 295 decisões daquele plano nacional, já consideradas inviáveis.

Outro problema também apontado na implementação do PNE 2001-2010 (BRASIL, 2001), identificado pelo levantamento do CNE acima mencionado (BRASIL, 2009), refere-se, justamente, à ausência de indicadores relativos aos objetivos e metas estabelecidos, dispositivos que viabilizam o acompanhamento e avaliação do desenvolvimento do plano. Aqui, também, os PEEs exibem o mesmo déficit, não sendo frequente, no conjunto desses planos, a indicação de quantitativos e prazos mensuráveis.

\subsection{Divulgação do plano aprovado}

Durante a análise dos PEEs, foi possível observar que 10 dos 11 (90,9\%) planos em questão apresentam aspectos associados à sua divulgação na lei de aprovação, a exceção de Alagoas que, embora o texto da lei não contenha estratégias de divulgação (ALAGOAS, 2006a), alguns dos eixos temáticos apresentados no documento do PEE (ALAGOAS, 2006b) evidenciam a necessidade de ações específicas associadas a esta importante estratégia de acompanhamento e controle social.

A observação das leis que aprovaram os PEEs possibilita perceber que são poucas as variações textuais que realmente implicam diferenças associadas à questão da sua divulgação. Neste sentido, pontuam-se aqui três dessas variações:

(i) cinco das dez leis que aprovaram os PEEs, no que se refere à sua divulgação, apresentam artigos praticamente iguais - Bahia (2006a), Mato Grosso (2008a), Mato Grosso do Sul (2003a), Pernambuco (2002a) e Tocantins (2007a) - seguindo, em linhas gerais, a redação do art. $6^{\circ}$ da Lei do PNE 2001-2011: "Os Poderes do Estado e dos Municípios empenhar-se-ão na divulgação deste Plano e da progressiva realização de seus objetivos e metas, para que a sociedade o conheça amplamente e acompanhe sua implementação" (BRASIL, 2001);

(ii) se as leis dos planos anteriormente mencionados determinam que o empenho para com sua divulgação se faça associar aos poderes do estado e dos municípios, outros a vinculam exclusivamente aos poderes do estado (AMAZONAS, 2008a; RIO DE JANEIRO, 2009a), aos "órgãos e as entidades do Poder Executivo do Estado" (GOIÁS, 2008a) ou à Secretaria de Estado da Educação e Cultura (PARAÍBA, 
2006a). No que se refere a esta ordenação convém observar que, se por um lado, a referida sequência indica restrições quanto à quantidade de poderes e/ou órgãos que deveriam empenhar-se na divulgação do plano - da designação mais genérica (poderes do estado e dos municípios) à de maior especificidade (Secretaria de Estado da Educação e Cultura) -, por outro, focaliza a responsabilidade, ampliando, a um só tempo, a possibilidade de acompanhamento e controle social;

(iii) a lei que aprovou o PEE do Pará, de forma lacunar, apenas determina, no art. $5^{\circ}$, que "A implantação e a execução do Plano Estadual de Educação serão objeto de ampla divulgação para a sociedade civil" (PARÁ, 2010a), sem mencionar uma possível responsabilidade para com tal ação. Além disso, o PEE do Pará, quiçá de modo contraditório, em diferentes momentos, destaca a importância da gestão democrática, que tem como alicerce a participação, transparência, descentralizarão e acompanhamento e controle social.

Em que pese o fato de grande parte dos PEEs estabelecerem no corpo da lei correspondente alguma referência à sua divulgação, apenas dois - Bahia e Rio de Janeiro - especificam, no próprio plano, formas e canais de como esta deverá ocorrer. O PEE da Bahia menciona que a SEDUC deverá responsabilizar-se pela publicação da versão aprovada do plano, bem como empenhar-se "para a sua divulgação e a progressiva realização dos objetivos e metas propostos" (BAHIA, 2006b, p. 4). Por sua vez, o PEE do Rio de Janeiro, além de ressaltar que a distribuição do PEE deverá atingir todas as unidades escolares, indica que deverá abarcar "as instituições da sociedade civil e divulgação em todas as mídias (internet, impressos, TV, rádios)" (RIO DE JANEIRO, 2009b, p. 66).

\section{Considerações Finais}

Conforme visto, o PNE 2001-2010 finda e - três anos e meio após - o PNE 2014-2024 principia num contexto infranacional marcado, por um lado, com apenas $46 \%$ dos estados com PEEs e, por outro, com aproximadamente $60 \%$ dos municípios com PMEs (IBGE, 2012) - o que explica, ao lado de outros aspectos, o insucesso daquele primeiro plano nacional -, impondo grandes desafios tanto a esses planos, que devem ser agora adequados às diretrizes, metas e estratégias previstas no novo PNE - Lei $\mathrm{n}^{\circ}$ 13.005/2014 (BRASIL, 2014) -, quanto aos planos ainda a serem elaborados que, igualmente, deverão expor sintonia em relação a este plano nacional.

Um primeiro conjunto de desafios a ser enfrentado pelos estados que virão reformular os seus PEEs consiste na superação de algumas debilidades documentais evidenciadas nas análises sobre a sua elaboração e aprovação, nomeadamente 
em termos das lacunas e imprecisões identificadas nos textos examinados, com vistas à consecução de um registro mais efetivo sobre este processo de construção.

No caso das lacunas, dimensão caracterizada pela ausência de informações que impede o estabelecimento de determinadas inferências sobre a construção desses PEEs, observou-se tratar de um problema recorrente entre todos os planos examinados, impactando, em maior grau, temáticas que remetem: (i) às datas de início e de término do processo de elaboração do PEE, ao lado das datas de tramitação nos Poderes Legislativo e Executivo; (ii) ao processo de elaboração do plano; (iii) à avaliação preliminar do plano elaborado, antes do seu envio ao Poder Legislativo; e (iv) às formas e canais destinados à divulgação do plano aprovado para a sociedade. No que tange às imprecisões, aspecto que se configura pelo generalismo de algumas das informações registradas sobre a construção desses PEEs, implicando entendimentos inexatos, ambíguos ou precários, verificou-se que as temáticas mais afetadas se relacionam: (i) ao processo de elaboração dos PEEs e (ii) à definição da responsabilidade para com a divulgação do plano aprovado.

Um segundo espectro de desafios decorre dos problemas identificados a partir da análise do próprio processo de elaboração e aprovação levado a efeito pelos estados para a construção dos seus planos, registrado, mesmo com lacunas e imprecisões, nos PEEs examinados, e que, em larga medida, entende-se que podem influenciar negativamente o seu processo de implantação local como: (i) o elevado tempo entre o início das discussões e sua aprovação na Casa legislativa correspondente; (ii) a não priorização do CEE como locus privilegiado para a coordenação e/ou construção do plano; (iii) a não realização de uma avaliação preliminar do plano; (iv) a ausência de diagnósticos efetivos relativos à realidade educacional local; (v) a declaração de um número excessivo de decisões (objetivos e metas); (vi) a ausência de indicadores relacionados às decisões do plano, que viabilizem o seu acompanhamento e avaliação e, ainda, (vii) a indefinição das estratégias que viabilizam a divulgação do plano aprovado.

Todavia, em termos gerais, o processo que envolveu a elaboração desses planos parece ter revestido-se de importantes significados histórico e sociopolítico no âmbito dos estados envolvidos, tanto por possibilitar a construção do seu primeiro PEE, quanto pelo fato de ter possibilitado, pelo menos declaradamente, o exercício local de processos participativos, em que pese o fato de os documentos examinados não possibilitarem inferências sobre a sua extensão e magnitude. Importante observar, conforme apontado na introdução desse artigo, as poucas investigações que versam sobre os PEEs, notadamente em termos da participação sociopolítica nas discussões e elaborações, avaliam essa participação como frágil, o que implica 
considerar a necessidade de um maior aprofundamento acerca desses processos em âmbito regional, para além do discurso oficial constante desses documentos, especialmente no momento em que novos planos se encontram em elaboração ou adequação com vistas ao atendimento das prescrições do novo PNE.

De um modo ou de outro, cabe finalmente ressaltar que a análise do processo que envolveu a elaboração e aprovação desses planos permite depreender que o mesmo foi perpassado por inúmeros desafios, entre eles, aqueles associados à ação pioneira de construir um PEE sob uma perspectiva democrática em estados, não raras vezes, carentes de condições infraestruturais. Se os reptos associados aos PEEs tiveram seu início demarcado, por vezes, já na dificuldade de encetar o seu processo de elaboração propriamente dito, por certo, não findou com sua aprovação na Assembleia Legislativa e tampouco na sua implantação, ressurgindo, agora, em face do PNE 2014-2024. 


\section{Elaboration and approval of educational plans ranging from national to local in Brazil}

\section{Abstract}

This article analyzes the elaboration and approval of the State Plans for Education (PEEs) sanctioned under the National Plan for Education (PNE) between 2001 and 2010 in Brazil. Through a content analysis of these plans and their laws of creation, this study aims to contribute to the adequacy and formulations implied by the latest PNE (2014-2024). The study traces the documental delicacy exposed by the PEEs, underscoring the gaps and imprecision that complicate drawing conclusions about its formulation, while it details the problems identified from the analysis of this process itself. It postulates, in general terms, that the formulation of these PEEs appears to have considerable historical and sociopolitical significance in the ambit of the involved states, marked by the mobilization of the local civil society. However, further in-depth analysis is required, especially in the face of the challenges presented by the new PNE.

Keywords: State plans for education (PEES). National plans for education (PNEs). Social participation. Democratic management of education.

\section{Elaboración y aprobación de planes de educación en Brasil: desde el nacional hasta el local}

\section{Resumen}

Este artículo tiene como objetivo analizar la elaboración y aprobación de los Planes estatales de Educación (PEEs) sancionadas durante la vigencia del Plan Nacional de Educación (PNE) 2001-2010. Bajo la perspectiva exploratoria y mediante el análisis de contenido de estos planes y sus leyes de creación, se busca contribuir en las adaptaciones y las formulaciones que el PNE 2014-2024 presupone. En conclusión traza el perfil, por una parte, de las debilidades documentales expuestas por estos PEEs, señalando imprecisiones y lagunas que dificultan inferencias acerca de su proceso de construcción y, en segundo lugar, los problemas identificados a partir del análisis del proceso en sí. Postula, en términos generales, que la construcción de estos PEEs parece haberse cubierto de gran significado histórico y sociopolítico dentro de los estados involucrados, marcado por la movilización de la sociedad civil local, pero que todavía demandan profundidad analítica, sobre todo en vista de los desafios que plantea la nueva PNE.

Palabras clave: Planes estatales de educación (PEEs). Planes nacionales de educación (PNEs). La participación social. La gestión democrática de la educación. 


\section{Referências}

ALAGOAS (Estado). Lei n ${ }^{\circ} 6.757$, de 3 de agosto de 2006. Aprova o Plano Estadual de educação para o período de 2006 a 2015, e dá outras providências. Diário Oficial [do] Estado de Alagoas, Maceió, 4 ago. 2006 a.

. Plano Estadual de Educação [de Alagoas]: PEE 2006/2015. Maceió: Secretaria Executiva de Educação, 2006b.

AMAZONAS (Estado). Lei no 3.268, 07 de julho de 2008. Aprova, no Estado do Amazonas, o Plano Estadual de Educação - PEE/AM e dá outras providências. Diário Oficial [do] Estado do Amazonas, Manaus, 7 jul. 2008a.

. Plano Estadual de Educação do Amazonas PEE-AM: uma construção da Sociedade. Manaus: Secretaria de Estado da Educação e Qualidade do Ensino, Conselho Estadual de Educação, 2008b.

ARIAS, V. A construção política do Plano Estadual de Educação (PEEPR) na gestão 2003-2006: controvérsias acerca do processo democrático no espectro do estado contemporâneo. Curitiba, 2007. 165 f. Dissertação (Mestrado em Educação) - Faculdade de Educação, Universidade Federal do Paraná.

BAHIA (Estado). Lei n ${ }^{\circ} 10.330$, de 15 de setembro de 2006. Aprova o Plano Estadual de Educação da Bahia - PEE e dá outras providências. Diário Oficial [do] Estado do Bahia, Salvador, 15 e 17 set. 2006a.

. Plano Estadual de Educação da Bahia. Salvador: Secretaria da Educação, set. 2006b.

BARDIN, L. Análise de conteúdo. 3. ed. Lisboa: Edições 70, 2004.

BEISIEGEL, C. R. O plano nacional de educação. Cadernos de Pesquisa, São Paulo, n. 106, p. 217-31, mar. 1999. doi:10.1590/S0100-15741999000100011

BOLLMAN, M. G. N. Revendo o Plano Nacional de Educação: proposta da sociedade brasileira. Educação \& Sociedade, Campinas, v. 31, n. 112, p. 657-76, jul./set. 2010. doi:10.1590/S0101-73302010000300002

BONAMINO, A. et al. Avaliação de políticas educacionais. In: BRASIL. Ministério da Educação. Secretaria de Educação Básica. Pradime: Programa de Apoio aos Dirigentes Municipais de Educação. Brasília, DF, 2006. p. 13376. (Caderno de textos, 1 ). 
BRASIL. Conselho Nacional de Educação. Portaria $C N E / C P n^{\circ} 10$, de 6 de agosto de 2009. Indicações para subsidiar a construção do Plano Nacional de Educação 2011-2020. Brasília, DF: Conselho Nacional de Educação, 2009.

. Constituição [de 1988] da República Federativa do Brasil. Diário Oficial da União, Brasília, DF, 5 out. 1988.

. Emenda Constitucional n ${ }^{0} 59$, de 11 de novembro de 2009. Acrescenta $\S 3^{\circ}$ ao art. 76 do Ato das Disposições Constitucionais Transitórias para reduzir, anualmente, a partir do exercício de 2009, o percentual da Desvinculação das Receitas da União incidente sobre os recursos destinados à manutenção e desenvolvimento do ensino de que trata o art. 212 da Constituição Federal, dá nova redação aos incisos I e VII do art. 208, de forma a prever a obrigatoriedade do ensino de quatro a dezessete anos e ampliar a abrangência dos programas suplementares para todas as etapas da educação básica, e dá nova redação ao $\S$ $4^{\circ}$ do art. 211 e ao $\S 3^{\circ}$ do art. 212 e ao caput do art. 214 , com a inserção neste dispositivo de inciso VI. Diário Oficial da União, Brasília, DF, 12 nov. 2009.

. Lei $\mathrm{n}^{\circ} 9.131$, de 24 de novembro de 1995. Altera dispositivos da Lei $\mathrm{n}^{\circ}$ 4.024, de 20 de dezembro de 1961, e dá outras providências. Diário Oficial da União, Brasília, DF, 25 nov. 1995.

BRASIL. Lei n. 9.394, de 20 de dezembro de 1996. Estabelece as Diretrizes e Bases da Educação Nacional. Diário Oficial da União, Brasília, DF, 23 dez. 1996.

. Lei $\mathrm{n}^{\mathrm{o}} 10.172$, de 09 de janeiro de 2001. Aprova o Plano Nacional de Educação (PNE). Diário Oficial da União, Brasília, DF, 10 jan. 2001.

. Lei $\mathrm{n}^{\circ} 12.796$, de 4 de abril de 2013. Altera a Lei no 9.394, de 20 de dezembro de 1996, que estabelece as diretrizes e bases da educação nacional, para dispor sobre a formação dos profissionais da educação e dar outras providências. Diário Oficial da União, Brasília, DF, 5 abr. 2013.

. Lei no 13.005 , de 25 de junho de 2014. Aprova o Plano Nacional de Educação - PNE e dá outras providências. Diário Oficial da União, Brasília, DF, 26 jun. 2014.

. Ministério da Educação e do Desporto. Plano decenal de educação para todos. Brasília, DF: MEC, 1993.

. Ministério da Educação. Secretaria de Educação Básica. Documento nortea dor para elaboração de Plano Municipal de Educação - PME. Brasília, DF: Ministério da Educação, 2005. 
BRASIL. Ministério da Educação. Secretaria Executiva. Conferência Nacional de Educação 2010 - Construindo o sistema nacional articulado de educação: o plano nacional de educação, diretrizes e estratégias de ação: documento final. Brasília, DF: Ministério da Educação, [s.d].

. Ministério da Educação. Instituto Nacional de Estudos e Pesquisas Educacionais Anísio Teixeira. Plano Nacional de Educação: proposta inicial dos procedimentos a serem seguidos. Brasília, DF: INEP, 1997.

. Projeto de Lei do Plano Nacional de Educação (PNE 2011-2020): projeto em tramitação no Congresso Nacional - PL no 8.035/2010. Brasília, DF: Edições Câmera, 2011. (Série Ação Parlamentar, 436).

. Projeto de Lei $\mathrm{n}^{\circ} 4.155$, de 10 de fevereiro de 1988. Aprova o Plano Nacional de Educação [proposta da sociedade brasileira]. Diário da Câmara dos Deputados, Brasília, DF, v. 53, n. 42, 12 mar. 1998a.

. Projeto de Lei $n^{\circ} 4.173$, de 11 de fevereiro de 1998. Institui o Plano Nacional de Educação [Proposta do Poder Executivo ao Congresso Nacional apensada ao PL 4.155/1998]. Brasília, DF: Câmara dos Deputados, 13 fev. 1998b.

CALDERÓN, A. I.; MARIM, V. Educação e políticas públicas: os conselhos municipais em questão. Teias - Revista da Faculdade de Educação da UERJ, Rio de Janeiro, v. 3, n. 6, p. 39-47, jul./dez. 2002.

. Participação popular: a escola como alvo do terceiro setor. In: SOUZA, D. B.; FARIA, L. C. M. (Orgs.). Desafios da educação municipal. Rio de Janeiro: DP\&A, 2003. p. 211-31.

CONAE 2014: documento de referência. Brasília, DF: Ministério da Eduicação, 2014.

CONTANDRIOPOULOS, A.-P. et al. Saber preparar uma pesquisa: definição, estrutura, financiamento. 2. ed. São Paulo: Abrasco; Rio de Janeiro: Hucitec, 1997.

CURY, C. R. J. O Plano Nacional de Educação: duas formulações. Cadernos de Pesquisa, São Paulo, v. 28, n. 104, p. 162-80, jul. 1998.

. O princípio da gestão democrática na educação pública. Gestão Democrática da Educação, Brasília, DF, n. 19, p. 14-19 out. 2005. 
DANTAS, G. K. G. Representações sociais sobre a escola pública paulista: do fórum "A Escola dos Nossos Sonhos" ao pesadelo do "Plano Estadual de Educação". Marília, 2008. 151 f. Dissertação (Mestrado em Educação) Faculdade de Filosofia e Ciências, Universidade Estadual Paulista Júlio de Mesquita Filho, 2008.

DAVIES, N. Fragilidades e desafios do financiamento em planos de educação: $10 \%$ do PIB são a salvação? In: SOUZA, D. B.; MARTINS, A. M. (Orgs.). Planos de educação no Brasil: planejamentos, políticas, práticas. São Paulo: Loyola, 2014. p. 183-205.

DIDONET, V. Plano Nacional de Educação (PNE). Brasília, DF: Plano, 2000.

DOURADO, L. F. Avaliação do Plano Nacional de Educação 2001-2009: questões estruturais e conjunturais de uma política. Educação \& Sociedade, Campinas, v. 31, n. 112, p. 677-705, jul./set. 2010. doi:10.1590/S010015741999000100011

DUARTE, M. R. T.; SANTOS, M. R. S. Educação e desenvolvimento: planejamento de ações governamentais e novos modos de regulação social? In: SOUZA, D. B.; MARTINS, A. M. (Orgs.). Planos de educação no Brasil: planejamentos, políticas, práticas. São Paulo: Loyola, 2014, p. 73-98.

FÓRUM Nacional em Defesa da Escola Pública. Plano Nacional de Educação: proposta da sociedade brasileira [Consolidado na plenária de encerramento do II CONED]. In: CONGRESSO NACIONAL DE EDUCAÇÃO, 2., 1997, Belo Horizonte, nov. 1997.

FRANCO, M. L. P. B. Análise de conteúdo. 2. ed. Brasília, DF: Liber, 2005.

GOHN, M. G. Conselhos gestores e participação sociopolitica. São Paulo: Cortez, 2001. (Coleção Questões da Nossa Época; 84).

O novo associativismo e o Terceiro Setor. Serviço Social \& Sociedade, São Paulo, v. 19, n. 58, p. 9-23, nov. 1998.

GOIÁS (Estado). Lei Complementar nº 62, de 9 de outubro de 2008. Aprova o Plano Estadual de Educação para o decênio 2008/2017 e dá outras providências. Diário Oficial [do] Estado de Goiás, Goiânia, 17 out. 2008a.

. Plano estadual de educação 2008-2017. Goiânia: Secretaria Estadual de Educação, Fórum Estadual de Educação, out. 2008b. 
INSTITUTO BRASILEIRO DE GEOGRAFIA E ESTATÍSTICA - IBGE. Diretoria de Pesquisas. Coordenação de População e Indicadores Sociais. Perfil dos municípios brasileiros 2011 [Pesquisa de Informações Básicas Municipais]. Rio de Janeiro: IBGE, 2012.

KETELE, J.-M.; ROEGIERS; X. Metodologia da recolha de dados: fundamentos dos métodos de observações, de questionários, de entrevistas e de estudo de documentos. Lisboa: Instituto Piaget, 1993 (Coleção Epistemologia e Sociedade).

LAVALLE, A. G.; HOUTZAGER, P. P.; CASTELLO, G. Representação política e organizações civis: novas instâncias de mediação e os desafios da legitimidade. Revista Brasileira Ciência e Sociedade, São Paulo, v. 21, n. 60, p. 43-66, fev. 2006.

LAVILLE, C.; DIONNE, J. A construção do saber: manual de metodologia da pesquisa em ciências humanas. Porto Alegre: Artmed; Belo Horizonte: Editora UFMG, 1999.

LUCHMANN, L. H. H. A representação no interior das experiências de participação. Lua Nova: Revista de Cultura e Política, São Paulo, n. 70, p. 139-170, 2007.

MATO GROSSO (Estado). Lei no 8.806, de 10 de janeiro de 2008. Dispõe sobre o Plano Estadual de Educação e dá outras providências. Diário Oficial [do] Estado do Mato Grosso, Cuiabá, 10 jan. 2008a.

. Plano Estadual de Educação 2006-2016. Cuiabá: SEDUC, CEE, Assembléia Legislativa, SINTEP, UNDIME, AME, $2008 \mathrm{~b}$.

MATO GROSSO DO SUL (Estado). Lei n ${ }^{\circ} 2.791$, de 30 de dezembro de 2003. Aprova o Plano Estadual de Educação de Mato Grosso e dá outras providências. Diário Oficial [do] Estado de Mato Grosso do Sul, Campo Grande, 31 dez. 2003a.

. Plano Estadual de Educação de Mato Grosso do Sul. Campo Grande: Secretaria de Estado de Educação, 2003b.

MENDES, D. C. V. R. Representação política e participação: reflexões sobre o déficit democrático. Revista Katálysis, Florianópolis, v. 10, n. 2, p. 143-153, jul.dez. 2007. 
MENDONÇA, E. F. Plano Nacional de Educação: desdobramentos na política nacional. In: TEIXEIRA, L. H. G. (Org.). $L D B$ e PNE: desdobramentos na política educacional brasileira. São Bernardo do Campo: UMESP, 2002. p. 1354. (Cadernos Anpae, 1).

MINAS GERAIS (Estado). Lei ${ }^{\circ}$ 19.481, de 12 de janeiro de 2011. Institui o plano Decenal de Educação do Estado. Diário Oficial [do] Estado de Minas Gerais, Belo Horizonte, 13 jan. 2011 [com PEE em anexo].

MONLEVADE, J. A. C. A importância do Conselho Municipal de Educação na elaboração, implantação e acompanhamento da execução do Plano Municipal de Educação. In: BRASIL. Ministério da Educação. Secretaria de Educação Básica. Programa Nacional de Capacitação de Conselheiros Municipais de Educação Pró-Conselho: caderno de referência. Brasília, DF: MEC/SEB, 2004, p. 32-43.

. Plano municipal da educação: fazer para acontecer. Brasília, DF: Idéa, 2002.

OLIVEIRA, R. F. O papel do Poder Legislativo na formulação das políticas educacionais. São Paulo, 2005, 262 f. Tese (Doutorado em Educação) Faculdade de Educação, Universidade de São Paulo.

. Revisando os mecanismos de formulação do Plano Nacional de Educação: considerações sobre o processo decisório. In: REUNIÃO ANUAL DA ASSOCIAÇÃO NACIONAL DE PÓS-GRADUAÇÃO E PESQUISA EM EDUCAÇÃO, 32., 2009, Caxambu. Anais... Rio de Janeiro: ANPEd, 2009.

OLIVEIRA JÚNIOR, L. B.; BERALDO, A. F. Vetar é preciso, educar não é preciso: os vetos presidenciais ao Plano Nacional de Educação. Revista Brasileira de Política e Administração da Educação, Piracicaba, v. 19, n. 1, p. 55-80, 2003.

ORGANIZAÇÃO DAS NAÇÕES UNIDAS PARAA EDUCAÇÃO, A CIÊNCIA E A CULTUR - UNESCO. Declaração Mundial sobre Educação para Todo: satisfação daas necessidades básicas de aprendizagem: Jomtien, 1990. Paris, 1998.

. Educação para todos: o compromisso de Dakar: texto adotado pelo Fórum Mundial de Educação, Dakar, Senegal-26 a 28 de abril de 2000. Brasília, DF: Unesco, 2001.

PARÁ (Estado). Lei n ${ }^{\circ} 7.441$, de 2 de julho de 2010. Aprova o Plano Estadual de Educação e dá outras providências. Diário Oficial [do] Estado do Pará [Suplemento 3], Belém, 02 jul. 2010 [com plano em anexo]. 
PARAÍBA (Estado). Lei no 8.043, de 30 de junho de 2006. Aprova o Plano Estadual de Educação e dá outras providências. Diário Oficial [do] Estado da Paraíba, João Pessoa, 01 jul. 2006a.

. Plano Estadual de Educação [da Paraíba]. João Pessoa, $2006 \mathrm{~b}$.

PERNAMBUCO (Estado). Lei $\mathrm{n}^{\circ} 12.252$, de 08 de julho de 2002. Aprova o Plano Estadual de Educação e dá outras providências. Diário Oficial do Estado de Pernambuco, Recife, 09 jul. 2002 [com plano em anexo].

PERONI, V. M. V.; FLORES, M. L. R. Sistema nacional, plano nacional e gestão democrática da educação no Brasil: articulações e tensões. In: SOUZA, D. B.; MARTINS, A. M. (Orgs.). Planos de educação no Brasil: planejamentos, políticas, práticas. São Paulo: Loyola, 2014, p. 147-165.

RIO DE JANEIRO (Estado). Lei n ${ }^{\circ} 4.528$, de 28 de março de 2005. Estabelece as diretrizes para a organização do sistema de ensino do estado do Rio de Janeiro. Diário Oficial [do] Estado do Rio de Janeiro, Rio de Janeiro, 12 de ago. 2005.

. Lei no 5.597, de 18 de dezembro de 2009. Institui o Plano Estadual de Educação - PEE-RJ, e dá outras providências. Diário Oficial [do] Estado do Rio de Janeiro, Rio de Janeiro, 19 de dezembro de 2009a.

. Plano Estadual de Educação do Rio de Janeiro. Rio de Janeiro, Secretaria de Educação, 2009b.

ROCHA, D. C. C.; MONLEVADE, J. A. C.; AGUiAR R. R. Financiamento e gestão orçamentária da educação. In: In: Ministério da Educação. Secretaria de Educação Básica. Pradime: Programa de Apoio aos Dirigentes Municipais de Educa. Brasília, DF: MEC.SEB, 2006, p. 73-118 (Caderno de Textos, 2).

RODRIGUES, L. C. Análises de conteúdo e trajetórias institucionais na avaliação de políticas públicas sociais: perspectivas, limites e desafios. CAOS - Revista Eletrônica de Ciências Sociais, João Pessoa, n. 16, p. 55-73, mar. 2011.

SAVIANI, D. Da nova LDB ao novo Plano Nacional de Educação: por uma outra política educacional. Campinas: Autores Associados, 1998.

SILVA, M. V.; PERONI, V. M. V. As mutações na oferta da educação pública no período pós-Constituição Federal e suas implicações na consolidação da gestão democrática. Revista Brasileira de Política e Administração da Educação, Recife, v. 29, n. 2, p. 243-262, mai./ago. 2014. 
SOUZA, D. B.; MENEZES, J. S. S. Estudo crítico-exploratório sobre os Planos Estaduais de Educação (PEEs) no Brasil: contribuições para formulações e reformulações decorrentes do novo Plano Nacional de Educação (PNE) - Relatório de pesquisa. Rio de Janeiro: Nephem/Uerj; Neephi/Unirio, jun. 2014.

SOUZA, S. A. A complexidade do processo de democratização e de participação na elaboração do Plano Estadual de Educação de Alagoas. Maceió, 2007. 145 f. Dissertação (Mestrado em Educação) - Centro de Educação, Universidade Federal de Alagoas.

TOCANTINS (Estado). Lei ${ }^{\circ} 1.859$, de 6 de dezembro de 2007. Aprova o Plano Estadual de Educação - PEE e adota outras providências. Diário Oficial [do] Estado do Tocantins, Palmas, 07 dez. 2007a.

. Plano Estadual de Educação [de Tocantins]. Palmas: Secretaria de Educação e Cultura, 2007b.

VALENTE, I. Plano Nacional de Educação. Rio de Janeiro: DP\&A, 2001.

VALENTE, I.; ROMANO, R. PNE: Plano Nacional de Educação ou carta de intenções? Educação \& Sociedade, Campinas, v. 23, n. 80, p. 96-107, set. 2002.

VALLE, B. B. R.; MENEZES, J. S. S.; VASCONCELOS, M. C. C. Plano Estadual de Educação do Rio de Janeiro: a trajetória de uma legislação. Rio de Janeiro: Quartet; Outras Letras, 2010.

\section{Informações sobre os autores:}

Donaldo Bello de Souza: Doutor em Educação pela Universidade Federal do Rio de Janeiro - UFRJ. Professor Associado na UERJ. Contato: donaldobello@gmail.com

Janaína Specht da Silva Menezes: Doutora em Educação pela Pontifícia Universidade Católica do Rio Grande do Sul - PUC-RS; Professora da Unirio. Contato: janainamenezes@hotmail.com 